\title{
Highly Accurate Quartic Force Fields, Vibrational Frequencies, and Spectroscopic Constants for Cyclic and Linear $\mathrm{C}_{3} \mathrm{H}_{3}{ }^{+}$
}

\author{
Xinchuan Huang, ${ }^{1 a}$ Peter R. Taylor, ${ }^{2 b}$ and Timothy J. Lee ${ }^{3 c *}$

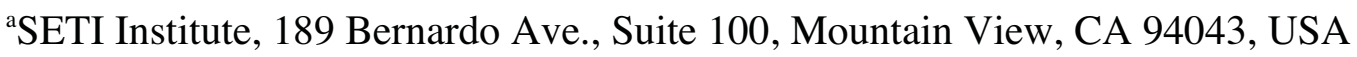 \\ ${ }^{b}$ Victorian Life Sciences Computation Initiative and Department of Chemistry, \\ University of Melbourne, Vic 3010, Australia \\ ${ }^{c}$ NASA Ames Research Center, Moffett Field, CA 94035-1000, USA
}

Corresponding Author Email: Timothy.J.Lee@nasa.gov

Title Running Head: Rovibrational Spectroscopic Constants for $\mathrm{C}_{3} \mathrm{H}_{3}{ }^{+}$from $\mathrm{Ab}$ Initio Theory

1.MS 245-6, Xinchuan.Huang-1@nasa.gov

22187 Grattan St, prtaylor@unimelb.edu.au

${ }^{3}$ MS 245-1, Timothy.J.Lee@nasa.gov, Corresponding author. 


\begin{abstract}
High levels of theory have been used to compute quartic force fields (QFFs) for the cyclic and linear forms of the $\mathrm{C}_{3} \mathrm{H}_{3}{ }^{+}$molecular cation, referred to as $\mathrm{c}-\mathrm{C}_{3} \mathrm{H}_{3}{ }^{+}$and $1-\mathrm{C}_{3} \mathrm{H}_{3}{ }^{+}$. Specifically the singles and doubles coupled-cluster method that includes a perturbational estimate of connected triple excitations, $\operatorname{CCSD}(\mathrm{T})$, has been used in conjunction with extrapolation to the one-particle basis set limit and corrections for scalar relativity and core correlation have been included. The QFFs have been used to compute highly accurate fundamental vibrational frequencies and other spectroscopic constants using both vibrational $2^{\text {nd }}$-order perturbation theory and variational methods to solve the nuclear Schrödinger equation. Agreement between our best computed fundamental vibrational frequencies and recent infrared photodissociation experiments is reasonable for most bands, but there are a few exceptions. Possible sources for the discrepancies are discussed. We determine the energy difference between the cyclic and linear forms of $\mathrm{C}_{3} \mathrm{H}_{3}{ }^{+}$, obtaining $27.9 \mathrm{kcal} / \mathrm{mol}$ at $0 \mathrm{~K}$, which should be the most reliable available. It is expected that the fundamental vibrational frequencies and spectroscopic constants presented here for $\mathrm{c}-\mathrm{C}_{3} \mathrm{H}_{3}{ }^{+}$ and $1-\mathrm{C}_{3} \mathrm{H}_{3}{ }^{+}$are the most reliable available for the free gas-phase species and it is hoped that these will be useful in the assignment of future high-resolution laboratory experiments or astronomical observations.
\end{abstract}




\section{Introduction}

The two lowest energy forms of $\mathrm{C}_{3} \mathrm{H}_{3}{ }^{+}$are cyclopropenyl cation and propargyl cation, though the energy difference between these is large - with the cyclic form being approximately 26 $\mathrm{kcal} / \mathrm{mol}$ lower in energy. ${ }^{1}$ Cyclopropenyl cation is the smallest aromatic carbocation, which explains its stability, but it should be noted that even with this large energy difference, it is common to find both isomers when they are produced in the gas-phase, suggesting that they form from different mechanisms. There has been considerable experimental and theoretical work on both isomers, and we refer the interested reader to Refs. 1-9 and references therein. Here, we discuss a few of the earlier works that relate to this study, but first we note that for convenience we shall refer to cyclopropenyl cation as $\mathrm{c}-\mathrm{C}_{3} \mathrm{H}_{3}{ }^{+}$and propargyl cation as $1-\mathrm{C}_{3} \mathrm{H}_{3}^{+}$, and when referring to both isomers we use $\mathrm{C}_{3} \mathrm{H}_{3}{ }^{+}$.

Our interest in $\mathrm{c}_{-} \mathrm{C}_{3} \mathrm{H}_{3}{ }^{+}$stems from astrochemistry. Cyclopropenylidene, $c-\mathrm{C}_{3} \mathrm{H}_{2}$, which possesses a large dipole moment, has been shown to be ubiquitous in the interstellar medium (ISM), ${ }^{10-12}$ and its main formation pathway has been proposed to be due to dissociative recombination of an electron with $\mathrm{c}_{-} \mathrm{C}_{3} \mathrm{H}_{3}{ }^{+13,14}$ Hence there has been considerable interest in detecting $\mathrm{c}-\mathrm{C}_{3} \mathrm{H}_{3}{ }^{+}$in the ISM for more than two decades. However, c- $\mathrm{C}_{3} \mathrm{H}_{3}{ }^{+}$possesses $D_{3 h}$ symmetry, resulting in no permanent dipole moment, and thus is not detectable via microwave (rotational) spectroscopy. Furthermore, there is no experimental high-resolution rovibrational spectrum available to analyze astronomical observations. In fact, until recently there was no gasphase spectrum of its vibrational frequencies, but instead only matrix isolation spectra or spectra from salts. ${ }^{15,16}$ That changed in 2002 when Dopfer et al ${ }^{2-4}$ used infrared photodissociation (IRDP) experiments to observe the $\mathrm{C}-\mathrm{H}$ stretching region of $\mathrm{C}_{3} \mathrm{H}_{3}{ }^{+}$complexed with various ligands. In 2010, Ricks et $\mathrm{al}^{5}$ improved upon these experiments by measuring the gas-phase infrared (IR) 
spectrum of the isomers of $\mathrm{C}_{3} \mathrm{H}_{3}{ }^{+}$that were associated with one Ar atom. The results of these latter two studies are generally consistent with the matrix isolation experiments, though many more bands were assigned in the Ricks et al IRPD experiment, going down to approximately $1100 \mathrm{~cm}^{-1}$. One inconsistency that was noted by Ricks et al, however, was that the assignment for the doubly degenerate $\mathrm{CH}$ stretching mode, $v_{4}\left(\mathrm{e}^{\prime}\right)$, at $3182 \mathrm{~cm}^{-1}$ was about $44 \mathrm{~cm}^{-1}$ higher than theory. They attributed this to problems in scaling factors for the theoretical calculations, and suggested that further theoretical work was needed. Thus one of the purposes of the present study was to provide theoretical predictions of the fundamental vibrational frequencies of both $\mathrm{C}_{3} \mathrm{H}_{3}{ }^{+}$wherein scaling is not required.

Determination of an anharmonic force field and fundamental vibrational frequencies has

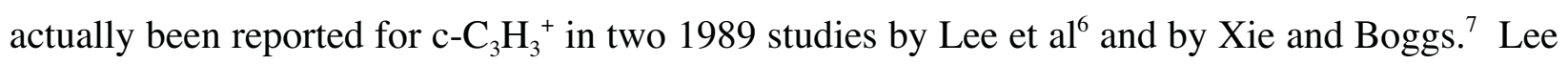
et al computed a full quartic force field $(\mathrm{QFF})$ at the Hartree-Fock level of theory to determine anharmonic corrections via second-order rovibrational perturbation theory which they then appended to harmonic frequencies computed at the second-order Møller-Plesset (MP2) pertubation level of theory. They reported an array of spectroscopic constants from their anharmonic analysis including anharmonic constants, vibration-rotation interaction constants, and quartic and sextic centrifugal distortion constants for $\mathrm{c}^{-} \mathrm{C}_{3} \mathrm{H}_{3}{ }^{+}$and its deuterated isotopologues. One interesting issue they uncovered was the fact that the standard formula used to compute the spectroscopic constants for symmetric top molecules ${ }^{17-19}$ can be incorrect when there is a non-totally symmetric, non-degenerate vibrational mode, as there is for $\mathrm{c}^{-} \mathrm{C}_{3} \mathrm{H}_{3}{ }^{+}$. The issue was discussed in some detail and Lee et al confirmed the modifications they made to the standard symmetric top formula by slightly perturbing the mass of one atom thereby slightly breaking the $D_{3 h}$ symmetry and forcing the SPECTRO program ${ }^{20}$ to use an asymmetric top analysis. Xie and Boggs used the MP4(SDQ) level of theory (fourth-order Møller-Plesset 
perturbation theory including single, double, and quadruple excitations, but excluding the more expensive triple excitations) to construct a partial potential energy surface that included diagonal force constants through sixth-order, but only second-order off diagonal force constants (in a local internal coordinate system). They then used an approximate variational approach to solve the nuclear Schrödinger equation. A detailed comparison of the two studies was presented in the Lee et al paper. In short, for the levels of theory used, both studies gave reasonable agreement with the matrix isolation experiments available at the time and with each other, though it is interesting to note that Lee et al obtained $3178 \mathrm{~cm}^{-1}$ for $v_{4}\left(\mathrm{e}^{\prime}\right)$ while Xie and Boggs obtained $3149 \mathrm{~cm}^{-1}$.

The higher energy isomer, $1-\mathrm{C}_{3} \mathrm{H}_{3}{ }^{+}$, has also received considerable attention from both theory and experiment. It was observed in both of the IRPD experiments mentioned above, ${ }^{2-5}$ and it has also been studied recently at high levels of theory by Botschwina and Oswald. ${ }^{8}$ Botschwina and Oswald used an explicitly correlated method, $\operatorname{CCSD}(\mathrm{T})-\mathrm{F} 12 \mathrm{x}(\mathrm{x}=\mathrm{a}, \mathrm{b}),{ }^{21,22}$ which is based on the singles and doubles coupled-cluster method that includes a perturbational correction for triple excitations, denoted $\operatorname{CCSD}(\mathrm{T}){ }^{23}$ They computed a five dimensional potential energy function, involving the totally symmetric modes, which included up through sixth-order diagonal constants and up through fourth-order off diagonal force constants, and solved the nuclear Schrödinger equation variationally. The five dimensions included the symmetric $\mathrm{CH}_{2}$ stretch, the free acetylenic $\mathrm{CH}$ stretch, the $\mathrm{CH}_{2}$ scissor mode, and the two $\mathrm{CC}$ stretching modes (a correction was applied to the antisymmetric $\mathrm{CH}_{2}$ fundamental to account for the neglect of anharmonic coupling). Botschwina and Oswald found generally good agreement with the IRPD experiment of Ricks et al.

More recently Botschwina and Oswald used the $\operatorname{CCSD}(\mathrm{T})-\mathrm{F} 12 \mathrm{x}(\mathrm{x}=\mathrm{a}, \mathrm{b})$ levels of theory to examine the equilibrium structure and harmonic vibrational frequencies of Ar complexes of both 
c- $\mathrm{C}_{3} \mathrm{H}_{3}{ }^{+}$and $1-\mathrm{C}_{3} \mathrm{H}_{3}{ }^{+9} \cdot$ They located three distinct minima for Ar complexes of both isomers, though one of the $C_{s}$ minima for $1-\mathrm{C}_{3} \mathrm{H}_{3}{ }^{+}$was noticeably lower in energy than the other two minima. For the $\mathrm{c}-\mathrm{C}_{3} \mathrm{H}_{3}{ }^{+}$isomer, all three minima were relatively close in energy. The results of this latter study reaffirmed Botschwina and Oswald's assignment of the $3238 \mathrm{~cm}^{-1}$ band in Ricks et al's IRPD experiments to the acetylenic $\mathrm{CH}$ stretch vibration in $1-\mathrm{C}_{3} \mathrm{H}_{3}{ }^{+}$.

The accuracy of state-of-the art ab initio predictions for fundamental vibrational frequencies has improved considerably in the last twenty years, and it is common now to determine fundamental vibrational frequencies to within a few wavenumbers $\left(\mathrm{cm}^{-1}\right)$ of high-resolution experiments (for example, see Refs. 24-27). To this end, theoretical spectroscopists predicted more than a decade $\mathrm{ago}^{28}$ that state-of-the art $a b$ initio predictions were becoming reliable enough that it should be possible to assign an astronomical spectrum using only ab initio predictions and without high-resolution laboratory experimental data for difficult species, such as small molecular anions and cations. This has now occurred only a few years ago when Cernicharo et $\mathrm{al}^{29}$ reported detecting the small molecular anion $\mathrm{C}_{5} \mathrm{~N}^{-}$in the C-rich star IRC +10216 and based their assignment on the $a b$ initio calculations of Aoki $^{30}$ and Botschwina and Oswald. ${ }^{31}$

Thus our goal in the present study is to compute highly accurate QFFs for the $\mathrm{c}-\mathrm{C}_{3} \mathrm{H}_{3}{ }^{+}$and 1$\mathrm{C}_{3} \mathrm{H}_{3}{ }^{+}$molecules, and to predict their rovibrational spectroscopic constants to very high accuracy. These data are of interest to astronomers now more than ever given that the Herschel Space Observatory is in operation and collecting high-resolution data, the NASA Stratospheric Observatory for Infrared Astronomy (SOFIA) has begun its series of initial science flights, and the James Webb Space Telescope (JWST), often referred to as the replacement to the Hubble Space Telescope, will launch later in this decade. Further, the Atacama Large Millimeter Array (ALMA) is set to start early science operations in late 2011. Some of the instruments for these 
telescopes operate at longer wavelengths and thus are not useful for rovibrational spectroscopy of $\mathrm{c}-\mathrm{C}_{3} \mathrm{H}_{3}{ }^{+}$, but they may be able to detect deuterium and ${ }^{13} \mathrm{C}$ isotopologues due to their increased sensitivity, which is especially interesting for isotopologues of $\mathrm{c}-\mathrm{C}_{3} \mathrm{H}_{3}{ }^{+}$. The parent isotopologue has no permanent dipole moment, hence it cannot be observed via rotational spectroscopy, but isotopologues that do not retain $D_{3 h}$ symmetry will exhibit a small permanent dipole moment since the center of nuclear charge and center of mass of the molecule will no longer be the same (and the molecule rotates about its center of mass). For $1-\mathrm{C}_{3} \mathrm{H}_{3}{ }^{+}$, the lowest energy vibration may be within range for instruments on all of the above telescopes, but since $1-\mathrm{C}_{3} \mathrm{H}_{3}{ }^{+}$possesses a permanent dipole moment, the parent isotopologue as well as all deuterium and ${ }^{13} \mathrm{C}$ isotopologues may be detectable. However, a full spectroscopic analysis of all deuterium and ${ }^{13} \mathrm{C}$ isotopologues of $\mathrm{c}-\mathrm{C}_{3} \mathrm{H}_{3}{ }^{+}$and $1-\mathrm{C}_{3} \mathrm{H}_{3}{ }^{+}$is beyond the scope of the present study, and will be reported separately. ${ }^{32}$

The Theoretical Approach is described in the next section, followed by Results and Discussion. Our Conclusions are presented in the final section.

\section{Theoretical Approach}

\section{A. Details of the Electronic Structure Methods}

We first describe details of the electronic structure calculations, including details of the corrections that have been included. In general, we follow the approach we have developed in recent years ${ }^{33,34}$ in which we extrapolate $\operatorname{CCSD}(\mathrm{T})$ energies to the one-particle basis set limit, ${ }^{35}$ followed by addition of corrections for scalar relativity ${ }^{36}$ and core correlation. The valence $\operatorname{CCSD}(\mathrm{T})$ calculations were performed in conjunction with Dunning's correlation consistent basis sets. ${ }^{37}$ We will denote the cc-pVXZ (X=T, Q, or 5) basis sets as TZ, QZ, or 5Z. A correction for scalar relativity is evaluated at the $\mathrm{CCSD}(\mathrm{T}) / \mathrm{TZ}$ level of theory using the Douglas- 
Kroll approximation. ${ }^{36}$ As we pointed out previously, ${ }^{33}$ the scalar relativity integrals lose precision when going beyond the TZ basis set, which is problematic for computing QFFs. Core correlation was included as a correction by performing $\operatorname{CCSD}(\mathrm{T})$ calculations, with and without the core correlated, using the Martin-Taylor basis set designed for this purpose. ${ }^{38}$

QFFs have been determined according to the prescription described previously. ${ }^{33,34}$ For both c$\mathrm{C}_{3} \mathrm{H}_{3}{ }^{+}$and $1-\mathrm{C}_{3} \mathrm{H}_{3}{ }^{+}$, a reference geometry was determined at the $\mathrm{CCSD}(\mathrm{T}) / 5 \mathrm{Z}$ level of theory with corrections for core correlation and scalar relativity taken into account. A grid of displacement geometries centered on this reference structure (and based on the symmetry internal coordinates discussed later) was then used for all calculations. The number of unique geometries was 1961 and 2479 for $\mathrm{c}_{-} \mathrm{C}_{3} \mathrm{H}_{3}{ }^{+}$and $1-\mathrm{C}_{3} \mathrm{H}_{3}{ }^{+}$, respectively. As indicated, $\mathrm{CCSD}(\mathrm{T})$ energies are extrapolated to the one-particle basis set limit using a three-point formula that experience has shown to be reliable. ${ }^{33,34,39}$ The scalar relativity and core-correlation corrections are added, and the energies are used in a least squares fit of a QFF for each molecule. For c- $\mathrm{C}_{3} \mathrm{H}_{3}{ }^{+}$, the 1961 unique energies were augmented to a redundant set of 3837 energies that was used to fit 460 unique coefficients in the QFF. The sum of the squared residuals was $1.31 \times 10^{-17}$ a.u. $^{2}$. For 1$\mathrm{C}_{3} \mathrm{H}_{3}{ }^{+}$, the 2479 unique energies were augmented to a redundant set of 4565 energies that was used to fit 572 unique coefficients in the QFF (sum of the squared residuals $=2.61 \times 10^{-17}$ a.u. $^{2}$ ). The final QFF for each molecule was then obtained by an analytical transformation to the exact minimum (i.e., to where the gradient terms are exactly zero). We note that it has been shown that some molecules with $\mathrm{C}-\mathrm{C}$ multiple bonds exhibit erratic behavior for bending frequencies, including molecules like acetylene, ethylene, and benzene, ${ }^{39-43}$ although cyclopropenylidene does not show this behavior. ${ }^{44}$ The problem is associated with ensuring that the one-particle basis set is properly balanced with respect to saturation in the lower angular momentum functions (i.e., $s$ and $p$ functions) and inclusion of higher angular momentum functions. Though we report only 
our best QFF here for both $\mathrm{c}-\mathrm{C}_{3} \mathrm{H}_{3}{ }^{+}$and $1-\mathrm{C}_{3} \mathrm{H}_{3}{ }^{+}$, we have examined in detail several QFFs for both isomers and found that neither suffers from this issue. All electronic structure calculations were performed with the MOLPRO 2006.1 program. $^{45}$

\section{B. Details of the Coordinate Systems and the Vibrational Methods}

For both molecules, the QFFs were determined in symmetry internal coordinates. For $1-\mathrm{C}_{3} \mathrm{H}_{3}{ }^{+}$, we use the following definition of symmetry internal coordinates:

$$
\begin{aligned}
& S_{1}\left(\mathrm{~A}_{1}\right)=R_{4}(C-H) \\
& S_{2}\left(\mathrm{~A}_{1}\right)=\left(R_{1 a}+R_{1 b}\right) / \sqrt{2} \\
& S_{3}\left(\mathrm{~A}_{1}\right)=\left(R_{2}[C=C]+R_{3}[C \equiv C]\right) / \sqrt{2} ; \\
& S_{4}\left(\mathrm{~A}_{1}\right)=\left(R_{2}[C=C]-R_{3}[C \equiv C]\right) / \sqrt{2} ; \\
& S_{5}\left(\mathrm{~A}_{1}\right)=\theta_{1}\left(\angle H_{a} C H_{b}\right) \\
& S_{6}\left(\mathrm{~B}_{1}\right)=\left(R_{1 a}-R_{1 b}\right) / \sqrt{2} ; \\
& S_{7}\left(\mathrm{~B}_{1}\right)=L I N 1\left(C-C-C-\vec{r}_{\text {out }}\right) \\
& S_{8}\left(\mathrm{~B}_{1}\right)=L I N 1\left(C-C-H-\vec{r}_{\text {out }}\right) \\
& S_{9}\left(\mathrm{~B}_{1}\right)=\left(\angle H a C C-\angle H_{b} C C\right) / \sqrt{2} ; \\
& S_{10}\left(\mathrm{~B}_{2}\right)=L I N 1\left(C-C-C-\vec{r}_{\text {in }}\right) \\
& S_{11}\left(\mathrm{~B}_{2}\right)=L I N 1\left(C-C-H-\vec{r}_{\text {in }}\right) \\
& S_{12}\left(\mathrm{~B}_{2}\right)=\tau\left(H_{a}-C-C-H_{b}\right)
\end{aligned}
$$

where the simple internal coordinates for $1-\mathrm{C}_{3} \mathrm{H}_{3}{ }^{+}$are given in Fig. 1 . Note that $S_{7}$ and $S_{8}$ are inplane bending modes and $S_{10}$ and $S_{11}$ are out-of plane bending modes. The definition of LINI(a$b-c-d)$ and $\tau(a-b-c-d)$ are taken from the INTDER program: ${ }^{46}$

$$
\begin{aligned}
& \operatorname{LIN} 1(a-b-c-d)=\sin ^{-1}\left[\vec{e}_{d} \cdot\left(\vec{e}_{b c} \times \vec{e}_{b a}\right)\right] \\
& \tau(a-b-c-d)=\sin ^{-1}\left[\vec{e}_{b a} \cdot\left(\vec{e}_{c b} \times \vec{e}_{c d}\right) /\left(\sin \phi_{a b c} \cdot \sin \phi_{b c d}\right)\right]
\end{aligned}
$$

where the $\mathbf{e}$ are unit vectors defined as $\mathbf{e}_{\mathrm{ab}}=\mathbf{e}_{\mathrm{b}}-\mathbf{e}_{\mathrm{a}}$. The reference vectors $\bar{r}_{\text {in }}$ and $\bar{r}_{\text {out }}$ were defined as follows: 


$$
\begin{aligned}
& \vec{r}_{\text {in }}=\vec{R}_{2} \times\left(\vec{R}_{1 a} \times \vec{R}_{1 b}\right) \\
& \vec{r}_{\text {out }}=\vec{R}_{2} \times \vec{r}_{\text {in }}=\vec{R}_{2} \times\left(\vec{R}_{2} \times\left(\vec{R}_{1 a} \times \vec{R}_{1 b}\right)\right)
\end{aligned}
$$

Fig.1 also gives the planar equilibrium and ground state (GS) vibrationally averaged structures for both $\mathrm{c}-\mathrm{C}_{3} \mathrm{H}_{3}{ }^{+}$and $1-\mathrm{C}_{3} \mathrm{H}_{3}{ }^{+}$, as well as the GS vibrationally averaged rotational constants. The vibrationally averaged quantities are the "position average," i.e., $r_{z}$, computed from $2^{\text {nd }}$-order perturbation theory. Symmetry relationships for the quadratic, cubic, and quartic force constants are given later.

For $\mathrm{c}-\mathrm{C}_{3} \mathrm{H}_{3}^{+}$, we use the exact same definition of symmetry internal coordinates as given by Lee et al. $^{6}$ They are repeated here for convenience:

$$
\begin{aligned}
& S_{1}\left(a_{1}\right)=\left(R_{1}+R_{2}+R_{3}\right) / \sqrt{3}, \\
& S_{2}\left(a_{1}\right)=\left(r_{1}+r_{2}+r_{3}\right) / \sqrt{3}, \\
& S_{3}\left(a_{2}\right)=\left(\alpha_{1}+\alpha_{3}+\alpha_{5}-\alpha_{2}-\alpha_{4}-\alpha_{6}\right) / \sqrt{6}, \\
& S_{4 a}(e)=\left(2 r_{1}-r_{2}-r_{3}\right) / \sqrt{6}, \\
& S_{5 a}(e)=\left(2 \beta_{1}-\beta_{2}-\beta_{3}\right) / \sqrt{6}, \\
& S_{6 a}(e)=\left(\alpha_{1}+\alpha_{2}+\alpha_{4}+\alpha_{5}-2 \alpha_{3}-2 \alpha_{6}\right) / \sqrt{12}, \\
& S_{7}\left(a_{2}^{\prime \prime}\right)=\left(\gamma_{1}+\gamma_{2}+\gamma_{3}\right) / \sqrt{3}, \\
& S_{8 a}\left(e^{\prime \prime}\right)=\left(2 \gamma_{1}-\gamma_{2}-\gamma_{3}\right) / \sqrt{6}, \\
& S_{4 b}(e)=\left(r_{2}-r_{3}\right) / \sqrt{2}, \\
& S_{5 b}(e)=\left(\beta_{2}-\beta_{3}\right) / \sqrt{2}, \\
& S_{6 b}(e)=\left(\alpha_{2}+\alpha_{5}-\alpha_{1}-\alpha_{4}\right) / 2, \\
& S_{8 b}\left(e^{\prime \prime}\right)=\left(\gamma_{2}-\gamma_{3}\right) / \sqrt{2},
\end{aligned}
$$

where the simple internal coordinates $R, r, \alpha, \beta$ are the bond lengths and bond angles defined in Fig. 2, and $\gamma$ refers to the out of plane bending angle for a given $\mathrm{C}-\mathrm{H}$ bond with respect to the plane defined by the three $\mathrm{C}$ atoms (see Fig. 2).

Fundamental vibrational frequencies were computed using either a vibrational variational method (VAR) or second-order perturbation theory (PT). ${ }^{17-19}$ The MULTIMODE program ${ }^{47}$ was used for the VAR calculations, while the SPECTRO program ${ }^{20}$ was used for the PT calculations, 
and for computing other spectroscopic constants. For $1-\mathrm{C}_{3} \mathrm{H}_{3}{ }^{+}$, the QFF was analytically transformed into a simple-internal, Morse-cosine coordinate system for the vibrational variational calculations. The benefits of using Morse coordinates for the stretches when using a QFF in vibrational variational calculations can be traced back to Meyer et $\mathrm{al}^{48}$ and Carter and Handy ${ }^{49}$ more than 20 years ago. Later in 1994 , Dateo et $\mathrm{al}^{50}$ first defined the Morse $\beta$ parameter solely on the computed force constants (i.e. $\left.\beta=-\mathrm{F}_{\mathrm{iii}} /\left(3 \mathrm{~F}_{\mathrm{ii}}\right)\right)$ instead of optimizing it with respect to experimental data. We follow this $\beta$ definition, which requires that the transformed diagonal cubic force constant for the stretch vanish. For $\mathrm{c}-\mathrm{C}_{3} \mathrm{H}_{3}{ }^{+}$, it is necessary to use a symmetry adapted Morse-cosine coordinate system (for the stretches and bends) because it is a ringed system. In addition, instead of the out-of-plane coordinates $\left(S_{7}, S_{8 a}, S_{8 b}\right)$, we use the sine of these coordinates. Rather than transforming the symmetry internal coordinate QFF into the symmetry adapted Morse-cosine-sine coordinate system, we refit the QFF. We note that transformation of the QFF into a Morse-cosine coordinate system is important (and in the case of $\mathrm{c}-\mathrm{C}_{3} \mathrm{H}_{3}{ }^{+}$, a Morse-cosine-sine coordinate system), otherwise some fundamental vibrational frequencies, in particular stretching frequencies, can be too high by tens of $\mathrm{cm}^{-1}$. As discussed in Ref. 50, the Morse-cosine coordinate system serves to build in the correct limiting behavior for the potential function.

\section{Results and Discussion}

\section{A. Equilibrium Structures and Harmonic Frequencies}

The equilibrium structure, equilibrium rotational constants, and harmonic frequencies for c$\mathrm{C}_{3} \mathrm{H}_{3}{ }^{+}$and $1-\mathrm{C}_{3} \mathrm{H}_{3}{ }^{+}$are presented in Tables 1 and 2, respectively. The equilibrium structures obtained in this work have somewhat shorter bond distances relative to those published recently ${ }^{8,9}$ using $\mathrm{CCSD}\left(\mathrm{T}^{*}\right)-\mathrm{F} 12 \mathrm{a}$, and the $\mathrm{HCH}$ angle determined here for $1-\mathrm{C}_{3} \mathrm{H}_{3}^{+}$is about $1^{\circ}$ 
larger. We note that the longer C-C bond in $1-\mathrm{C}_{3} \mathrm{H}_{3}{ }^{+}, R_{2}$ (see Fig. 1), is intermediate between a typical double and single bond length, but it is much closer to that in ethylene rather than ethane. Conversely, the corresponding harmonic frequency $\omega_{4}$ is intermediate between a typical double bond and a single bond, but its value is closer to that for ethane rather than ethylene. Previous authors have referred to this C-C bond as a "single bond," so we adopt that terminology here, but we note that it is intermediate between a single and double bond, which also means that there will not be free rotation of the terminal $\mathrm{CH}_{2}$ group about this bond. The shorter $\mathrm{C}-\mathrm{C}$ bond is very much like a typical triple bond both in its bond length and harmonic frequency.

The harmonic frequencies obtained here for $1-\mathrm{C}_{3} \mathrm{H}_{3}{ }^{+}$are in reasonable agreement with those given by Botschwina and Oswald ${ }^{8}$, though our stretching harmonic frequencies are generally a few $\mathrm{cm}^{-1}$ higher, consistent with the shorter bond lengths obtained in the present work. We note that we use a different convention for the symmetry labeling of the modes relative to Refs. 5 and 8 - essentially the $\mathrm{B}_{1}$ and $\mathrm{B}_{2}$ labels are reversed. That is, following the convention that Herzberg used for $C_{2 v}$ planar molecules, $\mathrm{B}_{1}$ is used for in-plane antisymmetric modes and $\mathrm{B}_{2}$ is reserved for out-of-plane vibrations, and that is the convention adopted here. For $\mathrm{c}-\mathrm{C}_{3} \mathrm{H}_{3}{ }^{+}$, the harmonic frequencies given in Table 1 are in reasonable agreement with the MP2 values from Ref. 6 and the MP4(SDQ) values of Ref. 7, given the differences in levels of theory.

As indicated previously, the energy difference between $\mathrm{c}-\mathrm{C}_{3} \mathrm{H}_{3}{ }^{+}$and $1-\mathrm{C}_{3} \mathrm{H}_{3}{ }^{+}$is about 26 $\mathrm{kcal} / \mathrm{mol}$, but the levels of theory used in the present study should yield a much more definitive value. The energy that we obtain at the minimum is $-115.7647467662 \mathrm{E}_{\mathrm{h}}$ and -115.717377491 $\mathrm{E}_{\mathrm{h}}$ for $\mathrm{c}-\mathrm{C}_{3} \mathrm{H}_{3}^{+}$and $1-\mathrm{C}_{3} \mathrm{H}_{3}^{+}$, respectively. The electronic energy difference is thus $10,396.4 \mathrm{~cm}^{-1}$. The anharmonic zero-point energies given by $2^{\text {nd }}$-order PT are $9841.5 \mathrm{~cm}^{-1}$ and $9208.0 \mathrm{~cm}^{-1}$, which includes the $E_{0}$ term (the polyatomic equivalent of the $a_{0}$ Dunham coefficient for diatomics). ${ }^{51}$ The corresponding MULTIMODE zero-point energies are $9823.7 \mathrm{~cm}^{-1}$ and 9189.1 
$\mathrm{cm}^{-1}$, for $\mathrm{c}_{-} \mathrm{C}_{3} \mathrm{H}_{3}{ }^{+}$and $1-\mathrm{C}_{3} \mathrm{H}_{3}{ }^{+}$, respectively. The $0 \mathrm{~K}$ energy difference we obtain is 27.9 $\mathrm{kcal} / \mathrm{mol}$, which is slightly larger than what has been reported experimentally. ${ }^{1}$ While the experimental value is not at $0 \mathrm{~K}$, it also has a few $\mathrm{kcal} / \mathrm{mol}$ uncertainty - see Ref. 1 and references therein for more details. The $27.9 \mathrm{kcal} / \mathrm{mol} 0 \mathrm{~K}$ value obtained in the present work should be the most reliable available.

\section{B. Fundamental Vibrational Frequencies and Spectroscopic Constants}

The GS vibrationally averaged structure and rotational constants, and the fundamental vibrational frequencies obtained for $\mathrm{c}_{-} \mathrm{C}_{3} \mathrm{H}_{3}{ }^{+}$in the present work are presented in Table 3. Other spectroscopic constants obtained from $2^{\text {nd }}$ order perturbation theory are presented in Table 4 (anharmonic constants) and Table 5 (vibration-rotation interaction constants, and quartic and sextic centrifugal distortion constants). For the variational calculations, we used four mode coupling and five mode coupling in order to demonstrate the convergence. Comparison of the fundamental vibrational frequencies for the two columns labeled VCI 4MR and VCI 5MR shows that indeed there is excellent convergence, with the largest difference being only $1.5 \mathrm{~cm}^{-1}$ for $v_{7}$. $4 \mathrm{MR} / 5 \mathrm{MR}$ refer to the number of modes coupled in the potential energy expansion formula, while 4-mode coupling was adopted in all Coriolis integrations. For most vibrational modes, the difference is $1.1 \mathrm{~cm}^{-1}$ or less, and for three of the modes the difference is less than $1 \mathrm{~cm}^{-1}$. Based on these comparisons and experience, we would estimate that the variational fundamentals are converged to better than $1.0 \mathrm{~cm}^{-1}$ for the VCI 5MR values. Comparison of the VCI 5MR results with the fundamentals obtained from $2^{\text {nd }}$-order perturbation theory shows good agreement with the two approaches, with the differences being consistent to what we usually find for tightly bound molecules that do not possess a large amplitude motion. Specifically, the largest difference is $3.8 \mathrm{~cm}^{-1}$ for $v_{2}$, but this mode is affected by a Fermi type 1 resonance with $2 v_{7}$. For 
most of the vibrational modes the difference is less than $3 \mathrm{~cm}^{-1}$, again showing that $2^{\text {nd }}$-order perturbation theory is a good approximation for solving the nuclear Schrödinger equation for a tightly bound molecule.

Our best results should be the VCI 5MR fundamentals. Comparison of these to the available experimental data shows reasonable agreement for the matrix isolation values where we might expect differences of up to $20 \mathrm{~cm}^{-1}$ or so due to a matrix shift. In fact, the largest differences between the matrix isolation results and our VCI 5MR values are only 9.6 and $12.0 \mathrm{~cm}^{-1}$ for $v_{3}$ and $v_{8}$, which are both determined indirectly (see Refs. 15 and 16 for details). Comparison of the VCI 5MR results to the IRPD values from Ricks et $\mathrm{al}^{5}$ shows very good agreement for $v_{5}$, but for $v_{4}$ we obtain a value that is $47.2 \mathrm{~cm}^{-1}$ lower than their assignment at $3182 \mathrm{~cm}^{-1}$. Thus our best estimate for $v_{4}$ is consistent with previous theory and calls into question their assignment. Further, the value we obtain for $v_{4}, 3134.8 \mathrm{~cm}^{-1}$, is more consistent with the assignment from Dopfer et al. ${ }^{2-4}$ One of the reasons we performed the variational calculations in the present study was to be certain that we had $v_{4}$ described properly since our $2^{\text {nd }}$-order perturbation theory results did not agree with the assignment from Ricks et al. Given the levels of theory used in the present study and the fact that we have ruled out any possible resonance issues in solving the vibration problem, we can definitively conclude that the $3182 \mathrm{~cm}^{-1}$ band observed by Ricks et al is either not representative of the free gas-phase spectrum for $\mathrm{c}-\mathrm{C}_{3} \mathrm{H}_{3}{ }^{+}$or it is due to a different vibrational mode or species. We have examined the variational CI results for possible combination bands or overtones in the variational calculations that might explain the band at $3182 \mathrm{~cm}^{-1}$, but none appear for either $\mathrm{c}-\mathrm{C}_{3} \mathrm{H}_{3}{ }^{+}$or $1-\mathrm{C}_{3} \mathrm{H}_{3}{ }^{+}$, at least not within $10 \mathrm{~cm}^{-1}$. There is a doubly degenerate band involving three quanta, $2 v_{6}+v_{5}$, that is very close to $3182 \mathrm{~cm}^{-1}$, but this seems unlikely. It may be that the band observed at $3182 \mathrm{~cm}^{-1}$ is shifted somewhat due to complexation with the Ar atom, or it may be due to a different species. 
Given the levels of theory used in the present study, the spectroscopic constants presented for c- $\mathrm{C}_{3} \mathrm{H}_{3}{ }^{+}$in Tables 4 and 5 should be highly accurate, and it is hoped these will be useful in the future assignment of high-resolution rovibrational spectra from either laboratory experiments or astronomical observations.

The vibrationally averaged structure and rotational constants, and the fundamental vibrational frequencies obtained for $1-\mathrm{C}_{3} \mathrm{H}_{3}{ }^{+}$in the present work are presented in Table 6 . These are "position averaged" values (i.e., $\mathrm{r}_{\mathrm{z}}$ ) computed with $2^{\text {nd }}$-order perturbation theory. Other spectroscopic constants obtained from $2^{\text {nd }}$ order perturbation theory are presented in Table 7 (anharmonic constants) and Table 8 (vibration-rotation interaction constants, and quartic and sextic centrifugal distortion constants). Comparison of the VCI 4MR and 5MR results contained in Table 6 shows that the variational calculations are converged to better than $1 \mathrm{~cm}^{-1}$, similar to the situation for $\mathrm{c}_{-} \mathrm{C}_{3} \mathrm{H}_{3}{ }^{+}$. In fact, the largest difference is only $0.8 \mathrm{~cm}^{-1}$ for $v_{7}$. Comparison of the VCI $5 \mathrm{MR}$ and $2^{\text {nd }}$-order perturbation theory fundamental vibrational frequencies for $1-\mathrm{C}_{3} \mathrm{H}_{3}{ }^{+}$ shows reasonable agreement, though not as good as found for $\mathrm{c}-\mathrm{C}_{3} \mathrm{H}_{3}{ }^{+}$. The largest differences occur for the C-H stretches $v_{1}$ and $v_{6}$, being 10.3 and $9.1 \mathrm{~cm}^{-1}$, respectively. We note that $v_{6}$ is involved with a significant Fermi type 2 resonance with $v_{3}+v_{7}$, though the difference between the two components of the resonance is fairly consistent between $2^{\text {nd }}$-order perturbation theory and VCI 5MR (35.7 versus $\left.34.0 \mathrm{~cm}^{-1}\right)$. Differences between $2^{\text {nd }}$-order perturbation theory and VCI 5MR for the other fundamental vibrational frequencies are more in line with the differences we found for $\mathrm{c}_{-} \mathrm{C}_{3} \mathrm{H}_{3}{ }^{+}$. Interestingly, the agreement between $2^{\text {nd }}$-order perturbation theory and VCI $5 \mathrm{MR}$ for the $2 v_{4}$ overtone and the $v_{12}+v_{4}$ combination band is not nearly as good, which is expected as one moves into the realm of less pure states and stronger coupling.

Agreement between our best VCI 5MR fundamental vibrational frequencies and those obtained by Botschwina and Oswald ${ }^{8}$ using the $\operatorname{CCSD}\left(\mathrm{T}^{*}\right) \mathrm{F}-12 \mathrm{a} / \mathrm{VTZ}-\mathrm{F} 12$ level of theory is 
modest. The largest differences occur for $v_{1}\left(15 \mathrm{~cm}^{-1}\right)$ and $v_{4}\left(27 \mathrm{~cm}^{-1}\right)$. There are many possible sources for these differences, with the most significant probably being the use of an approximate $(\mathrm{T})$ contribution by Botschwina and Oswald, their neglect of core correlation, and their neglect of most coupling to non-totally symmetric vibrational degrees of freedom in solving the variational nuclear Schrödinger equation.

Comparison of our best VCI 5MR results with the experiments of Ricks et al shows reasonable agreement for most of the assignments with a few exceptions. Our best value for $v_{1}$ agrees very well, confirming the conclusion by Botschwina and Oswald ${ }^{9}$ that the $3238 \mathrm{~cm}^{-1}$ band observed by Ricks et al is essentially a free acetylenic C-H stretch. The agreement for $v_{2}, v_{3}$, and $v_{4}$ is also very good, with differences all less than about $10 \mathrm{~cm}^{-1}$. Agreement for the overtone band $2 v_{4}$ is reasonable, being about twice the difference for the $v_{4}$ fundamental, and agreement for $v_{6}$ is also reasonable as the assignment by Ricks et al falls between the two components of the Fermi type 2 resonance between $v_{6}$ and $v_{3}+v_{7}$. Agreement for $v_{5}, v_{10}$, and the combination band $v_{12}+v_{4}$ is more modest, however. Botschwina and Oswald ${ }^{8}$ have already questioned the reliability of the assignment for the totally symmetric mode $v_{5}$. Given that the lowest energy structure found for $1-\mathrm{C}_{3} \mathrm{H}_{3}{ }^{+} \bullet$ Ar has the Ar atom out of plane and over the $\mathrm{C}-\mathrm{C}$ single bond, and that this structure is quite a bit lower in energy than the other minima, ${ }^{9}$ it seems plausible that the $\mathrm{C}-\mathrm{C}$ single bond stretch $v_{5}$ would be significantly impacted in the complex. This same reasoning could be applied to $v_{10}$, which is described as a $\mathrm{CH}_{2}$ out-of plane wag, and to the combination band $\mathrm{v}_{12}+\mathrm{v}_{4}$ since $v_{12}$ is an out-of plane bending mode that involves the CCC backbone. Thus, the discrepancies found between the assignments of Ricks et al and our VCI 5MR results can reasonably be attributed to shifts in the vibrational frequencies as a result of complexation for $1-\mathrm{C}_{3} \mathrm{H}_{3}{ }^{+}$.

For $l-\mathrm{C}_{3} \mathrm{H}_{3}{ }^{+}$, the effects of scalar relativistic corrections are small: $\sim-5 \mathrm{E}-5 \AA$ on the C-H bond lengths and $\sim-3 \mathrm{E}-4 \AA$ on the $\mathrm{CC}$ bonds; less than or equal to $0.4 \mathrm{~cm}^{-1}$ on harmonic frequencies; 
and -6 to $0 \mathrm{~cm}^{-1}$ for the vibrational fundamentals. As expected from previous experience, corecorrelation effects are much larger on the geometry (-1.3E-3 $\AA$ for the $\mathrm{CH}$ bonds and $-3 \mathrm{E}-3 \AA$ for the $\mathrm{CC}$ bonds) and harmonic frequencies $\left(+2\right.$ to $\left.+7 \mathrm{~cm}^{-1}\right)$, but only slightly larger for the fundamentals ( +2 to $+8 \mathrm{~cm}^{-1}$, except $+10.7 \mathrm{~cm}^{-1}$ for $v_{10}$ ). For $c-\mathrm{C}_{3} \mathrm{H}_{3}{ }^{+}$, the effects of scalar relativity corrections are smaller than found for $l-\mathrm{C}_{3} \mathrm{H}_{3}{ }^{+}:-2.1 \mathrm{E}-4 \AA$ for $R_{\mathrm{CC}} ;-5.5 \mathrm{E}-5 \AA$ for $r_{\mathrm{CH}}$; 0.0-0.5 $\mathrm{cm}^{-1}$ for harmonic frequencies; and -1 to $+2 \mathrm{~cm}^{-1}$ for fundamentals (except $+8 \mathrm{~cm}^{-1}$ for $\left.v_{3}\right)$. However, core-correlation effects are larger: $-5.4 \mathrm{E}-3 \AA$ for $R_{\mathrm{CC}} ;-1.4 \mathrm{E}-3 \AA$ for $r_{\mathrm{CH}} ;+2$ to +7 $\mathrm{cm}^{-1}$ for harmonic frequencies; and +3 to $+9 \mathrm{~cm}^{-1}$ for fundamentals (except $+0.3 \mathrm{~cm}^{-1}$ for $v_{6}$ ). More details are available upon request.

Given the levels of theory used in the present study, the spectroscopic constants presented for 1- $\mathrm{C}_{3} \mathrm{H}_{3}{ }^{+}$in Tables 7 and 8 should be highly accurate, and it is hoped these will be useful in the future assignment of high-resolution rovibrational spectra from either laboratory experiments or astronomical observations.

\section{Quartic Force Fields}

For completeness, the best QFFs computed in this work are given in Tables 9 through 12 . Specifically, Table 9 contains the quadratic and cubic force constants and Table 10 the quartic force constants for $\mathrm{c}_{-} \mathrm{C}_{3} \mathrm{H}_{3}{ }^{+}$. Table 11 contains the quadratic and cubic force constants and Table 12 the quartic force constants for $1-\mathrm{C}_{3} \mathrm{H}_{3}{ }^{+}$. These are given in symmetry internal coordinates and symmetry relationships between the force constants are given in the tables. The force constants presented are based on the following quartic expansion:

$$
\mathrm{V}=\frac{1}{2} \sum_{\mathrm{i}, \mathrm{j}} \mathrm{F}_{\mathrm{ij}} \Delta_{\mathrm{i}} \Delta_{\mathrm{j}}+\frac{1}{6} \sum_{\mathrm{i}, \mathrm{j}, \mathrm{k}} \mathrm{F}_{\mathrm{ijk}} \Delta_{\mathrm{i}} \Delta_{\mathrm{j}} \Delta_{\mathrm{k}}+\frac{1}{24} \sum_{\mathrm{i}, \mathrm{j}, \mathrm{k}, \mathrm{l}} \mathrm{F}_{\mathrm{ijkl}} \Delta_{\mathrm{i}} \Delta_{\mathrm{j}} \Delta_{\mathrm{k}} \Delta_{\mathrm{l}}
$$


where the summations are unrestricted. We note that for the force constant labels for $1-\mathrm{C}_{3} \mathrm{H}_{3}{ }^{+}$, we have labeled modes 10, 11, and 12 as x, y, and z, respectively, in order to avoid confusion. So, for example, the diagonal quadratic force constant for mode 10 is given as $\mathrm{F}_{\mathrm{xx}}$.

\section{Conclusions}

Accurate $\operatorname{CCSD}(\mathrm{T})$ QFFs have been computed for the $\mathrm{c}-\mathrm{C}_{3} \mathrm{H}_{3}{ }^{+}$and $1-\mathrm{C}_{3} \mathrm{H}_{3}{ }^{+}$molecular cations. Extrapolation to the one-particle basis set limit has been included as well as corrections for scalar relativity and core correlation. Anharmonic spectroscopic constants have been determined from $2^{\text {nd }}$-order perturbation theory and fundamental vibrational frequencies have been evaluated from $2^{\text {nd }}$-order perturbation theory and from variational calculations. Agreement between $2^{\text {nd }}$-order perturbation theory and variational CI calculations for the fundamental vibrational frequencies is very good. Agreement between our computed fundamental vibrational frequencies and recent IRPD experiments is good with a few exceptions. The $3182 \mathrm{~cm}^{-1}$ band assigned in one recent IRPD experiment ${ }^{5}$ to $v_{4}$ for $\mathrm{c}_{-} \mathrm{C}_{3} \mathrm{H}_{3}{ }^{+}$does not agree well with our calculations where we obtain $3134.8 \mathrm{~cm}^{-1}$ (VCI 5MR), but our value does agree well with other recent IRPD experiments. ${ }^{2-4}$ We have examined our VCI calculations for possible combination and overtone bands, but can find only one band that could be a reasonable match and this requires three quanta. Hence we conclude that the $3182 \mathrm{~cm}^{-1}$ band may be a combination or overtone band that is perturbed somewhat by the presence of the Ar atom, or it may be due to a different species. For $1-\mathrm{C}_{3} \mathrm{H}_{3}{ }^{+}$, agreement between the IRPD experiments and our variational calculations for the fundamental vibrational frequencies (plus one overtone and one combination band) is reasonable except for $v_{5}, v_{10}$, and the combination band $v_{12}+v_{4}$. However, a recent ab initio study ${ }^{9}$ that explored the potential energy surface of $1-\mathrm{C}_{3} \mathrm{H}_{3}{ }^{+}$interacting with an Ar atom shows one minimum quite a bit 
lower than the others, and this structure would likely exhibit perturbations to $v_{5}, v_{10}$, and the combination band $v_{12}+v_{4}$, so a plausible explanation for these discrepancies is given.

The fundamental vibrational frequencies and spectroscopic constants presented here for c$\mathrm{C}_{3} \mathrm{H}_{3}{ }^{+}$and $1-\mathrm{C}_{3} \mathrm{H}_{3}{ }^{+}$should be the most reliable available for the free gas-phase species and it is hoped that they will be useful in the assignment of future high-resolution laboratory experiments or astronomical observations. Finally, we compute what should be the most reliable energy difference between the $\mathrm{c}-\mathrm{C}_{3} \mathrm{H}_{3}{ }^{+}$and $1-\mathrm{C}_{3} \mathrm{H}_{3}{ }^{+}$, obtaining a value of $27.9 \mathrm{kcal} / \mathrm{mol}$ at $0 \mathrm{~K}$.

\section{Acknowledgments}

The authors gratefully acknowledge support from the NASA Herschel GO Program, Cycle 0 TR/LA PID 1022, and the NASA grant 08-APRA08-0050. XH acknowledges the financial support by NASA/SETI Institute Cooperative Agreement NNX09AI49A. Part of this work of this work was performed when PRT was a visiting professor at the Department of Chemistry, University of Copenhagen, and the hospitality of Prof. Kurt Mikkelsen and the theoretical chemistry group is gratefully acknowledged. 


\section{References}

(1) Burgess, P. C.; Holmes, J. L.; Mommers, A. A.; Szulejko, J. E. J. Am. Chem. Soc. 1984, $106,521$.

(2) Dopfer, O.; Roth, D.; Maier, J. P. J. Am. Chem. Soc. 2002, 124, 494.

(3) Dopfer, O.; Roth, D.; Maier, J. P. Int. J. Mass Spectrom. 2002, 218, 281.

(4) Roth, D.; Dopfer, O.; Roth, D. Phys. Chem. Chem. Phys. 2002, 4, 4855.

(5) Ricks, A. M.; Douberly, G. E.; Schleyer, P. v. R.; Duncan, M. A. J. Chem. Phys. 2010, $132,051101$.

(6) Lee, T. J.; Willetts, A.; Gaw, J. F.; Handy, N. C. J. Chem. Phys. 1989, 90, 4330.

(7) Xie, Y.; Boggs, J. E. J. Chem. Phys. 1989, 90, 4320.

(8) Botschwina, P.; Oswald, R. Chem. Phys. 2010, 378, 4.

(9) Botschwina, P.; Oswald, R. J. Chem. Phys. 2011, 134, 044305.

(10) Thaddeus, P.; Vrtilek, J. M.; Gottlieb, C. A. Astrophys. J. 1985, 299, L63.

(11) Bell, M. B.; Feldman, P. A.; Matthews, H. E.; Avery, L. W. Astrophys. J. 1986, 311, 1989.

(12) Oike, T.; Kawaguchi, K.; Takano, S.; Nakai, N. Pub. Astron. Soc. Japan 2004, 56, 4310.

(13) Kamata, H.; Yamamoto, S.; Saito, S. Chem. Phys. Lett. 1987, 140, 221. and references therein.

(14) Smith. D. Chem. Rev. (Washington, D.C.) 1992, 92, 1473.

(15) Breslow, R.; Groves, J. T. J. Am. Chem. Soc. 1970, 92, 984.

(16) Wyss. M.; Riaplov, E.; Maier, J. P. J. Chem. Phys. 2001, 114, 10355; Craig, N. C.; Pranata, J.; Reinganum, S. J.; Sprague, J. R.; Stevens, P. S. J. Am. Chem. Soc. 1986, $108,4378$. 
(17) Mills, I. M. in Molecular Spectroscopy - Modern Research, ed. by K. N. Rao and C. W. Mathews (Academic Press, New York, 1972).

(18) Papousek, D.; Aliev, M. R. Molecular Vibrational-Rotational Spectra (Elsevier, Amsterdam, 1982).

(19) Watson, J. K. G; in Vibrational Spectra and Structure, edited by Durig, J. R. (Elsevier, Amsterdam, 1977), Vol. 6, pp. 1-89.

(20) SPECTRO program, version 3.0 (1996), written by Gaw, J. F.; Willets, A.; Green, W. H.; Handy, N. C.

(21) Adler, T. B.; Knizia, G.; Werner, H.-J. J. Chem. Phys. 2007, 127, 221106.

(22) Knizia, G.; Adler, T. B.; Werner, H.-J. J. Chem. Phys. 2009, 130, 054104.

(23) K. Raghavachari, G. W. Trucks, J. A. Pople, and M. Head-Gordon, Chem. Phys. Lett. 1989, $157,479$.

(24) Martin, J. M. L.; Lee, T. J. Chem. Phys. Lett. 1992, 200, 502.

(25) Wong, A. T.; Bacskay, G. B. Mol. Phys. 1993, 79, 819.

(26) Martin, J. M. L.; Lee, T. J.; Taylor, P. R. J. Chem. Phys. 1998, 108, 676.

(27) Martin, J. M. L.; Lee, T. J.; Taylor, P. R.; Francios, J.-P. J. Chem. Phys. 1995, 103, 2589.

(28) Lee T. J.; Dateo, C. E. Spectrochim. Acta. 1999, 55A, 739.

(29) Cernicharo, J.; Guelin, M.; Agundez, M.; McCarthy, M. C.; Thaddeus, P. Astrophys. J. 2008, 688, L83.

(30) Aoki, K. Chem. Phys. Lett. 2000, 323, 55.

(31) Botschwina, P.; Oswald, R. J. Chem. Phys. 2008, 129, 044305.

(32) Huang, X.; Lee, T. J. Astrophys. J. 2011, to be submitted.

(33) Huang, X.; Lee, T. J. J. Chem. Phys. 2008, 129, 044312. 
(34) Huang, X.; Lee, T. J. J. Chem. Phys. 2009, 131, 104301.

(35) Martin, J. M. L.; Lee, T. J. Chem. Phys. Lett. 1996, 258, 136.

(36) Douglas, M.; Kroll, N. M. Ann. Phys. 1974, 82, 89; Hess, B. A. Phys. Rev. A 1985, 32,$756 ; \mathbf{1 9 8 6}, 33,3742$.

(37) Dunning, T. H., Jr. J. Chem. Phys. 1989, 90, 1007.

(38) Martin, J. M. L.; Taylor, P. R. Chem. Phys. Lett. 1994, 225, 473.

(39) Huang, X.; Valeev, E. F.; Lee, T. J. J. Chem. Phys. 2010, 133, 244108.

(40) Lee, T. J.; Allen, W. D.; Schaefer, H. F. J. Chem. Phys. 1987, 87, 7062.

(41) Simandiras, E. D.; Rice, J. E.; Lee, T. J.; Amos, R. D.; Handy, N. C. J. Chem. Phys. 1988, $88,3187$.

(42) Martin, J. M. L.; Taylor, P. R.; Lee, T. J., Chem. Phys. Lett. 1997, 275, 414.

(43) Moran, D.; Simmonett, A. C.; Leach, F. E.; Allen, W. D.; Schleyer, P. v. R.; Schaefer, H. F. J. Am. Chem. Soc. 2006, 128, 9342.

(44) Lee, T. J.; Huang, X.; Dateo, C. E. Mol. Phys. 2009, 107, 1139.

(45) Werner, H.-J. et al. MOLPRO, version 2006.1, a package of ab initio programs; 2006; see http://www.molpro.net.

(46) INTDER 2005 is a general program written by W. D. Allen and co-workers, which performs vibrational analysis and higher order nonlinear transformations, 2005.

(47) Carter, S.; Bowman, J. M.; Handy, N. C. Theor. Chem. Acc. 1998, 100, 191; Bowman, J. M.; Carter, S.; Huang, X. Int. Rev. Phys. Chem. 2003, 22, 533.

(48) Meyer, W.; Botschwina, P.; Burton, P. J. Chem. Phys. 1986, 84, 891.

(49) Carter, S.; Handy, N. C. J. Chem. Phys. 1987, 87, 4294.

(50) Dateo, C. E.; Lee, T. J.; Schwenke, D. W. J. Chem. Phys. 1994, 101, 5853.

(51) Truhlar, D. G.; Isaacson, A. D. J. Chem. Phys. 1991, 94, 357, and references therein. 
Figures and Tables

Figure 1. Equilibrium structures, and vibrationally averaged structures (italic numbers) and rotational constants of $\mathrm{c}-\mathrm{C}_{3} \mathrm{H}_{3}{ }^{+}$and $1-\mathrm{C}_{3} \mathrm{H}_{3}{ }^{+}$determined from our best QFF. See text for details.
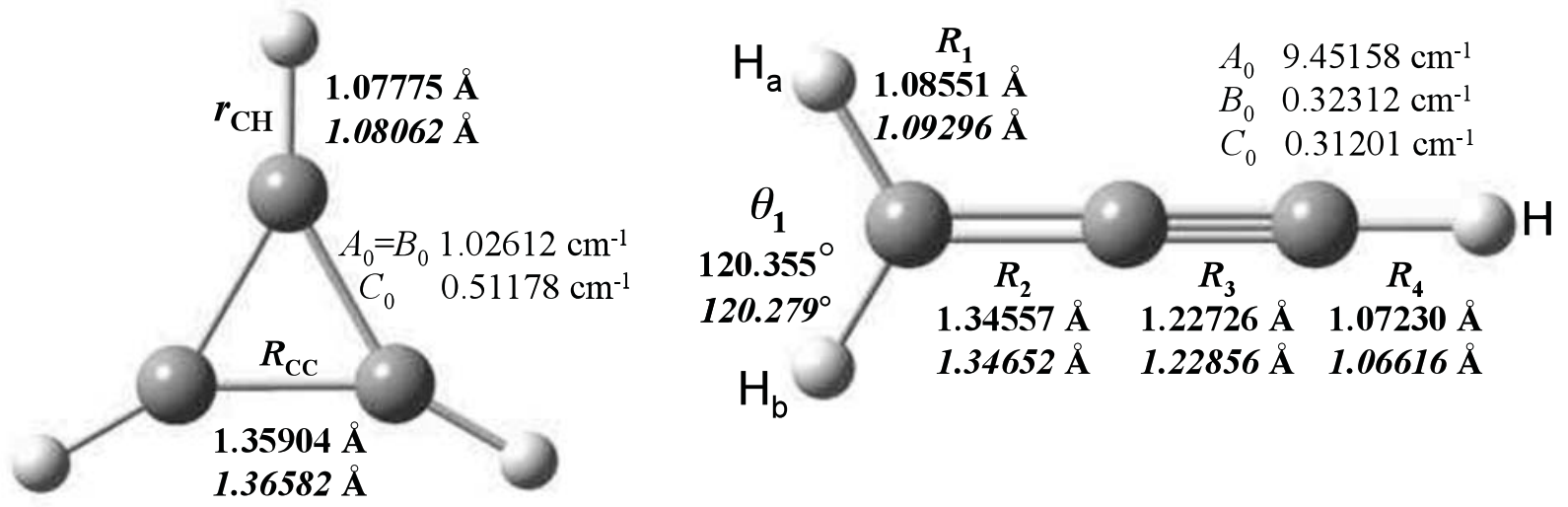
Fig. 2. Internal coordinate definitions used for the $\mathrm{c}-\mathrm{C}_{3} \mathrm{H}_{3}{ }^{+}$cation.

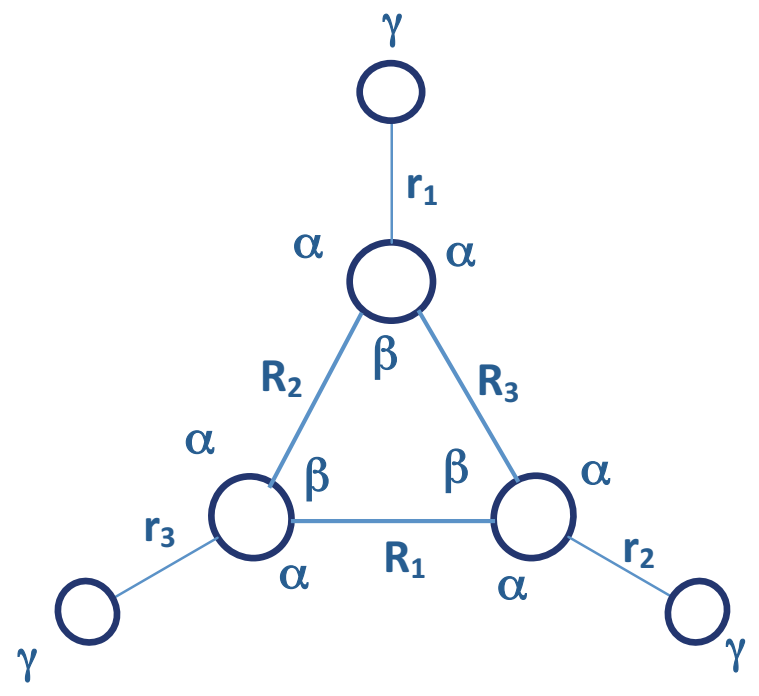


Table 1. Equilibrium structure $(\AA / \mathrm{deg})$, rotational constants $\left(\mathrm{cm}^{-1}\right)$, and harmonic frequencies $\left(\mathrm{cm}^{-1}\right)$ for $\mathrm{c}_{-} \mathrm{C}_{3} \mathrm{H}_{3}{ }^{+}$, determined from our best QFF $(\mathrm{CCSD}(\mathrm{T}) / \mathrm{cc}-\mathrm{pV}(\mathrm{T}, \mathrm{Q}, 5) \mathrm{Z}$ extrapolation + core-correlation + scalar relativistic corrections). See text for more details.

\begin{tabular}{lr|ccr}
\hline \multicolumn{2}{c|}{ Geometry } & \multicolumn{3}{c}{ Harmonic Vibrational Frequencies } \\
\hline$R(\mathrm{C}-\mathrm{C})$ & Parameters & Mode & Symmetry and Description & \multicolumn{1}{c}{ Freq } \\
$r(\mathrm{C}-\mathrm{H})$ & 1.3590363 & $\omega_{1}$ & $a_{1}{ }^{\prime}$ (breathing, C-H str - C-C str) & 3312.3 \\
$A_{\mathrm{e}}=B_{\mathrm{e}}$ & 1.0777461 & $\omega_{2}$ & $a_{1}{ }^{\prime}$ (breathing, C-H str + C-C str) & 1650.8 \\
$C_{\mathrm{e}}$ & 1.03260 & $\omega_{3}$ & $a_{2}{ }^{\prime}$ (in-plane internal torsion) & 1058.2 \\
$\angle \mathrm{C}-\mathrm{C}-\mathrm{H}$ & 0.51630 & $\omega_{4}$ & $e^{\prime}$ (in-plane deformation) & 3265.1 \\
$\angle \mathrm{C}-\mathrm{C}-\mathrm{C}$ & 150.0 & $\omega_{5}$ & $e^{\prime}$ (in-plane wagging) & 1326.7 \\
& 60.0 & $\omega_{6}$ & $e^{\prime}$ (in-plane scissoring) & 946.0 \\
& & $\omega_{7}$ & $a_{2}{ }^{\prime \prime}$ (symmetric out-of-plane bends) & 764.5 \\
& & $\omega_{8}$ & $e^{\prime \prime}$ (asymmetric out-of-plane bends) & 1023.4 \\
\hline
\end{tabular}


Table 2. Equilibrium structure $(\AA / \mathrm{deg})$, rotational constants $\left(\mathrm{cm}^{-1}\right)$, and harmonic frequencies $\left(\mathrm{cm}^{-1}\right)$ for $l-\mathrm{C}_{3} \mathrm{H}_{3}{ }^{+}$, determined from our best QFF $(\mathrm{CCSD}(\mathrm{T}) / \mathrm{cc}-\mathrm{pV}(\mathrm{T}, \mathrm{Q}, 5) \mathrm{Z}$ extrapolation + core-correlation + scalar relativistic corrections). See text and Fig.1 for more details and the definition of $R_{1}-R_{4}$ and $\theta_{1}$.

\begin{tabular}{cr|ccr}
\hline \multicolumn{2}{c|}{ Geometry } & \multicolumn{3}{c}{ Harmonic Vibrational Frequencies } \\
\hline$R_{1}$ & Mode & Symmetry and Description & Freq \\
$R_{2}$ & 1.085506 & $\omega_{1}$ & $a_{1}(\mathrm{C}-\mathrm{H}$ str $)$ & 3367.15 \\
$R_{3}$ & 1.345571 & $\omega_{2}$ & $a_{1}\left(\mathrm{CH}_{2}\right.$ sym str $)$ & 3122.73 \\
$R_{4}$ & 1.227265 & $\omega_{3}$ & $a_{1}(\mathrm{C} \equiv \mathrm{C}$ str $)$ & 2131.15 \\
$\theta_{1}$ & 1.072298 & $\omega_{4}$ & $a_{1}\left(\mathrm{CH}_{2}\right.$ bending $)$ & 1483.44 \\
$\angle \mathrm{C}-\mathrm{C}-\mathrm{H}$ & 120.355 & $\omega_{5}$ & $a_{1}(\mathrm{C}-\mathrm{C}$ str $)$ & 1137.60 \\
$\angle \mathrm{C}-\mathrm{C}-\mathrm{C}$ & 180.0 & $\omega_{6}$ & $b_{1}\left(\mathrm{CH}_{2}\right.$ anti-sym str $)$ & 3232.42 \\
& 180.0 & $\omega_{7}$ & $b_{1} \mathrm{CH}_{2}$ group rocking & 1039.76 \\
$A_{\mathrm{e}}$ & & $\omega_{8}$ & $b_{1}(\mathrm{CCH}$ in-plane linear bend $)$ & 631.00 \\
$B_{\mathrm{e}}$ & 9.53209 & $\omega_{9}$ & $b_{1}(\mathrm{CCC}$ in-plane linear bend $)$ & 292.51 \\
$C_{\mathrm{e}}$ & 0.32329 & $\omega_{10}$ & $b_{2}\left(\mathrm{CH} \mathrm{H}_{2}\right.$ out-of-plane wag $)$ & 1120.50 \\
& 0.31269 & $\omega_{11}$ & $b_{2}(\mathrm{CCH}$ out-of-plane linear bend $)$ & 882.00 \\
& & $\omega_{12}$ & $b_{2}(\mathrm{CCC}$ out-of-plane linear bend $)$ & 254.71 \\
\hline
\end{tabular}


Table 3. Vibrationally averaged structure $(\AA / \mathrm{deg})$, rotational constants $\left(\mathrm{cm}^{-1}\right)$, and vibrational fundamental frequencies $\left(\mathrm{cm}^{-1}\right)$ for $\mathrm{c}_{-} \mathrm{C}_{3} \mathrm{H}_{3}{ }^{+}$, determined from our best QFF. $2^{\text {nd }}$-order Perturbation Theory $\left(2^{\text {nd }} \mathrm{PT}\right)$ and vibrational variational CI results, where $n \mathrm{MR}$ represents the highest mode coupling level in the potential term expansions, are presented and compared to experiment. See text for more details.

\begin{tabular}{|c|c|c|c|c|c|c|}
\hline \multicolumn{7}{|c|}{ Zero-Point Structure and Rotational Constants } \\
\hline & $\mathrm{R}_{\mathrm{z}}(\mathrm{C}-\mathrm{C})$ & 1.3658234 & & $A_{0}=B_{0}$ & 1.02610 & \\
\hline & $\mathrm{R}_{\mathrm{z}}(\mathrm{C}-\mathrm{H})$ & 1.0806204 & & $C_{0}$ & 0.51178 & \\
\hline \multicolumn{7}{|c|}{ Anharmonic Vibrational Analysis } \\
\hline Mode & $2^{\text {nd }}-\mathrm{PT}$ & $\begin{array}{r}\text { VCI } \\
4 \mathrm{MR}\end{array}$ & $\begin{array}{l}\mathrm{VCI} \\
5 \mathrm{MR}\end{array}$ & $\operatorname{Exp}^{\mathrm{c}}$ & $\operatorname{Exp}^{\mathrm{d}}$ & Exp \\
\hline$v_{1}\left(a_{1}^{\prime}\right)$ & $\begin{array}{r}3176.6 \\
->3171.7^{a}\end{array}$ & 3174.8 & 3175.4 & 3183 & & \multirow{15}{*}{$\begin{array}{r}3125 \pm 4^{\mathrm{e}} \\
3129^{\mathrm{f}} \\
3130^{\mathrm{g}}\end{array}$} \\
\hline$v_{2}\left(a_{1}^{\prime}\right)$ & $\begin{array}{r}1618.3 \\
->1620.7^{b}\end{array}$ & 1622.0 & 1622.1 & 1626 & & \\
\hline$v_{3}\left(a_{2}^{\prime}\right)$ & 1040.3 & 1039.3 & 1040.6 & $(1031)$ & & \\
\hline$v_{4}\left(e^{\prime}\right)$ & 3131.7 & 3133.8 & 3134.8 & 3138 & 3182 & \\
\hline$v_{5}\left(e^{\prime}\right)$ & 1299.6 & 1295.9 & 1296.2 & 1290 & 1293 & \\
\hline$v_{6}\left(e^{\prime}\right)$ & 924.2 & 925.9 & 927.0 & 927 & & \\
\hline$v_{7}\left(a_{2}^{\prime \prime}\right)$ & 756.6 & 755.6 & 757.1 & 758 & & \\
\hline$v_{8}\left(e^{\prime \prime}\right)$ & 1004.5 & 1000.9 & 1002.0 & (990) & & \\
\hline ZPE & 9841.5 & 9833.2 & 9834.0 & & & \\
\hline \multicolumn{6}{|c|}{$\begin{array}{l}{ }^{\mathrm{a}} \text { Fermi type } 1 \text { resonance with } 2 v_{2} \\
{ }^{\mathrm{b}} \text { Fermi type } 1 \text { resonance with } 2 v_{7}\end{array}$} & \\
\hline \multicolumn{6}{|c|}{${ }^{\mathrm{c}}$ Refs. 15 and 16.} & \\
\hline \multicolumn{6}{|c|}{${ }^{\mathrm{d}}$ Ref. 5.} & \\
\hline \multicolumn{6}{|c|}{${ }^{\mathrm{e}}$ Ref. 2.} & \\
\hline \multicolumn{6}{|c|}{${ }^{\mathrm{f}}$ Ref. 3.} & \\
\hline${ }^{8} \mathrm{R}$ & & & & & & \\
\hline
\end{tabular}


Table 4. The $x_{s t}$ and $g_{t t}$ anharmonic constant matrices for $\mathrm{c}^{-} \mathrm{C}_{3} \mathrm{H}_{3}{ }^{+}$determined from our best QFF. All values are in $\mathrm{cm}^{-1}$. See text for more details.

\begin{tabular}{|c|c|c|c|c|c|c|c|c|}
\hline Mode & 1 & 2 & 3 & 4 & 5 & 6 & 7 & 8 \\
\hline 1 & -18.820 & & & & & & & \\
\hline 2 & -2.749 & -3.596 & & & & & & \\
\hline 3 & -6.862 & -3.610 & -1.030 & & & & & \\
\hline 4 & -75.767 & -2.134 & -5.084 & -28.685 & & & & \\
\hline 5 & 1.634 & -12.513 & -6.429 & 0.943 & -6.667 & & & \\
\hline 6 & -7.881 & -2.876 & -1.420 & -6.993 & -3.418 & -1.647 & & \\
\hline 7 & -7.703 & -3.452 & 0.727 & -6.373 & -0.076 & -1.681 & -1.811 & \\
\hline 8 & -7.001 & -2.323 & 3.143 & -5.993 & 1.398 & 1.159 & -1.541 & 0.077 \\
\hline Mode & 4 & 5 & 6 & 8 & & & & \\
\hline 4 & 9.532 & & & & & & & \\
\hline 5 & -0.684 & 3.384 & & & & & & \\
\hline 6 & 0.064 & -0.361 & 0.762 & & & & & \\
\hline 8 & -0.073 & -0.287 & -0.182 & 0.578 & & & & \\
\hline
\end{tabular}


Table 5. Vibration-rotation interaction constants and quartic and sextic centrifugal distorsion constants for $\mathrm{c}-\mathrm{C}_{3} \mathrm{H}_{3}{ }^{+}$. See text for more details.

\begin{tabular}{|c|c|c|c|c|c|c|c|c|c|c|}
\hline \multicolumn{3}{|c|}{ Vib-rot Constant $(\mathrm{MHz})$} & \multicolumn{4}{|c|}{ Distortion Constant } & \multicolumn{4}{|c|}{ Watson $S$ reduction } \\
\hline Mode & $\alpha^{\mathrm{B}}$ & $\alpha^{\mathrm{C}}$ & & $(\mathrm{MHz})$ & & $(\mathrm{Hz})$ & & $(\mathrm{MHz})$ & & $(\mathrm{Hz})$ \\
\hline 1 & 92.1 & 45.9 & $\tau_{\text {aaaa }}^{\prime}$ & -0.291 & $\Phi_{\text {aaa }}$ & 0.183 & $D_{J}$ & 0.073 & $H_{J}$ & 0.259 \\
\hline 2 & 90.0 & 44.9 & $\tau_{\text {bbbb }}^{\prime}$ & -0.291 & $\Phi_{\mathrm{bbb}}$ & 0.335 & $D_{J K}$ & -0.122 & $H_{J K}$ & -1.119 \\
\hline 3 & $-13.8^{\mathrm{a}}$ & 16.6 & $\tau_{\text {cccc }}^{\prime}$ & -0.023 & $\Phi_{\mathrm{ccc}}$ & 0.001 & $D_{K}$ & 0.055 & $H_{K J}$ & 1.466 \\
\hline 4 & 85.7 & 42.2 & $\tau_{\text {aabb }}^{\prime}$ & -0.291 & $\Phi_{\mathrm{aab}}$ & 0.956 & $d_{1}$ & 0.000 & $H_{K}$ & -0.605 \\
\hline 5 & -15.2 & 42.1 & $\tau_{\text {aacc }}^{\prime}$ & -0.047 & $\Phi_{\mathrm{abb}}$ & -0.179 & $d_{2}$ & 0.000 & $h_{1}$ & 0.000 \\
\hline 6 & $137.8^{\mathrm{a}}$ & 21.7 & $\tau_{\text {bbcc }}^{\prime}$ & -0.047 & $\Phi_{\mathrm{aac}}$ & -0.171 & & & $h_{2}$ & 0.000 \\
\hline 7 & $-109.8^{\mathrm{a}}$ & -10.9 & & & $\Phi_{\mathrm{acc}}$ & 0.002 & & & $h_{3}$ & -0.038 \\
\hline 8 & $23.7^{\mathrm{a}}$ & -26.4 & & & $\Phi_{\mathrm{bcc}}$ & 0.002 & & & & \\
\hline & & & & & $\Phi_{\mathrm{bbc}}$ & -0.171 & & & & \\
\hline & & & & & $\Phi_{\mathrm{abc}}$ & -0.342 & & & & \\
\hline
\end{tabular}

${ }^{\mathrm{a}}$ Modes for which Coriolis resonance has been taken into account. 
Table 6. Vibrationally averaged structure $(\AA / \mathrm{deg})$, rotational constants $\left(\mathrm{cm}^{-1}\right)$, and vibrational fundamental frequencies $\left(\mathrm{cm}^{-1}\right)$ for $1-\mathrm{C}_{3} \mathrm{H}_{3}{ }^{+}$, determined from our best QFF. $2^{\text {nd }}$-order Perturbation Theory $\left(2^{\text {nd }} \mathrm{PT}\right)$ and vibrational variational CI results, where $n \mathrm{MR}$ represents the highest mode coupling level in the potential term expansions, are presented and compared to experiment. See text for more details and Fig. 1 for coordinate definition.

\begin{tabular}{|c|c|c|c|c|}
\hline \multicolumn{5}{|c|}{ Zero-Point Structure and Rotational Constants } \\
\hline$R_{1}$ & 1.095770 & & $\theta_{1}$ & 120.284 \\
\hline$R_{2}$ & 1.353993 & & $A_{0}$ & 9.40357 \\
\hline$R_{3}$ & 1.236271 & & $B_{0}$ & 0.31956 \\
\hline$R_{4}$ & 1.068242 & & $C_{0}$ & 0.30861 \\
\hline \multicolumn{5}{|c|}{ Anharmonic Vibrational Analysis } \\
\hline & \multirow[t]{2}{*}{$2^{\text {nd }} \mathrm{PT}$} & \multicolumn{2}{|c|}{ Variational CI } & \multirow[t]{2}{*}{$\operatorname{Exp}^{d}$} \\
\hline & & $4 \mathrm{MR}$ & $5 \mathrm{MR}$ & \\
\hline$v_{1}\left(A_{1}\right)$ & 3228.7 & 3238.9 & 3239.0 & $\begin{array}{r}3238 \\
3139^{\circ}\end{array}$ \\
\hline$v_{2}^{\mathrm{a}}\left(A_{1}\right)$ & 2997.0 & 2999.2 & 2998.7 & 3004 \\
\hline$v_{3}\left(A_{1}\right)$ & 2084.0 & 2082.2 & 2082.2 & 2077 \\
\hline$v_{4}\left(A_{1}\right)$ & 1429.8 & 1433.7 & 1434.4 & 1445 \\
\hline$v_{5}^{\mathrm{b}}\left(A_{1}\right)$ & 1128.5 & 1131.9 & 1131.8 & 1222 \\
\hline \multirow{2}{*}{$v_{6}^{\mathrm{c}}\left(B_{1}\right)$} & 3061.9 & 3070.8 & 3071.0 & \multirow{5}{*}{$\begin{array}{l}3093 \\
3113^{f}\end{array}$} \\
\hline & 3097.6 & 3104.5 & 3105.0 & \\
\hline$v_{7}\left(B_{1}\right)$ & 998.0 & 999.8 & 1000.6 & \\
\hline$v_{8}\left(B_{1}\right)$ & 598.0 & 607.8 & 607.7 & \\
\hline$v_{9}\left(B_{1}\right)$ & 294.0 & 294.2 & 294.8 & \\
\hline$v_{10}\left(B_{2}\right)$ & 1054.6 & 1057.9 & 1058.1 & 1111 \\
\hline$v_{11}\left(B_{2}\right)$ & 859.7 & 861.8 & 861.9 & \\
\hline$v_{12}\left(B_{2}\right)$ & 249.3 & 251.8 & 251.7 & \\
\hline $2 v_{4}$ & 2836.9 & 2856.8 & 2857.8 & 2878 \\
\hline$v_{12}+v_{4}$ & 1676.4 & 1695.2 & 1695.5 & 1755 \\
\hline$v_{5}+v_{3}$ & 3193.4 & 3202.0 & 3201.8 & $\begin{array}{c}3191 / 3243^{2} \\
3184 / 3238^{9}\end{array}$ \\
\hline
\end{tabular}

${ }^{\text {a }}$ Fermi resonance Type 1 with $2 v_{4}$

${ }^{\mathrm{b}}$ Fermi resonance Type 2 with $v_{11}+v_{12}$

${ }^{\mathrm{c}}$ Fermi resonance Type 2 with $v_{3}+v_{7}$

${ }^{\mathrm{d}}$ Ref. 5.

${ }^{\mathrm{e}}$ Ref. 2.

${ }^{\mathrm{f}}$ Ref. 3.

${ }^{\mathrm{g}}$ Ref. 4. 
Table 7. The matrix of anharmonic constants $x_{s t}$ for $l-\mathrm{C}_{3} \mathrm{H}_{3}{ }^{+}$, determined from our best QFF. All values are in $\mathrm{cm}^{-1}$. See text for more details.

\begin{tabular}{c|rrrrrrrrrrrr}
\hline Mode & \multicolumn{1}{|c}{1} & \multicolumn{1}{c}{2} & \multicolumn{1}{c}{3} & \multicolumn{1}{c}{4} & 5 & 6 & 7 & 8 & 9 & 10 & 11 & 12 \\
\hline 1 & -54.889 & & & & & & & & & & & \\
2 & -0.146 & -27.831 & & & & & & & & & & \\
3 & -5.779 & -1.751 & -8.478 & & & & & & & & \\
4 & -1.230 & -31.736 & -3.781 & -2.102 & & & & & & & & \\
5 & 1.635 & -2.248 & -15.680 & -3.110 & -0.881 & & & & & & & \\
6 & -0.335 & -113.563 & -0.901 & -21.757 & -1.314 & -32.215 & & & & & & \\
7 & -1.719 & -11.150 & -2.502 & -17.450 & -2.595 & -11.681 & -3.844 & & & & & \\
8 & -20.642 & -2.628 & -11.108 & -6.735 & -2.675 & -2.796 & -8.808 & -5.238 & & & & \\
9 & -2.301 & -0.575 & -8.408 & -2.241 & 3.420 & -0.498 & -1.749 & -2.636 & -0.679 & & & \\
10 & -3.339 & -10.399 & -6.230 & -5.004 & -3.113 & -20.36 & -4.794 & -16.356 & -2.625 & -9.210 & & \\
11 & -20.948 & -1.829 & 0.992 & -2.515 & -3.018 & -1.529 & -3.121 & 27.704 & 1.906 & -13.415 & -6.040 & \\
12 & -2.493 & -1.797 & -5.193 & -3.296 & 7.240 & -1.374 & -2.602 & 1.710 & 21.446 & -9.393 & -4.744 & -2.569 \\
\hline
\end{tabular}


Table 8. Vibration-rotation interaction constants and quartic and sextic centrifugal distorsion constants for $1-\mathrm{C}_{3} \mathrm{H}_{3}{ }^{+}$. See text for more details.

\begin{tabular}{|c|c|c|c|c|c|c|c|c|c|c|c|}
\hline \multirow[b]{2}{*}{ Mode } & \multicolumn{3}{|c|}{ Vib-rot constants (MHz) } & \multicolumn{4}{|c|}{ Distortion Constant } & \multicolumn{4}{|c|}{ Watson $S$ reduction } \\
\hline & $\alpha^{\mathrm{A}}$ & $\alpha^{\mathrm{B}}$ & $\alpha^{C}$ & & $(\mathrm{MHz})$ & & $(\mathrm{Hz})$ & & $(\mathrm{MHz})$ & & $(\mathrm{Hz})$ \\
\hline 1 & -21.277 & 25.909 & 24.454 & $\tau_{\text {aаaа }}^{\prime}$ & -85.377 & $\Phi_{\text {aаa }}$ & 4809.680 & $D_{J}$ & 0.003 & $H_{J}$ & -0.001 \\
\hline 2 & 4879.106 & 6.846 & 11.688 & $\tau_{\text {bbbb }}^{\prime}$ & -0.012 & $\Phi_{\mathrm{bbb}}$ & 0.000 & $D_{J K}$ & 0.479 & $H_{J K}$ & 4.988 \\
\hline 3 & 151.243 & 55.273 & 51.836 & $\tau_{\text {cccc }}^{\prime}$ & -0.010 & $\Phi_{\mathrm{ccc}}$ & 0.000 & $D_{K}$ & 20.862 & $H_{K J}$ & -2267.423 \\
\hline 4 & -3188.803 & $3.755^{\mathrm{a}}$ & 11.156 & $\tau_{\text {aabb }}^{\prime}$ & -1.931 & $\Phi_{\text {aab }}$ & -742.911 & $d_{1}$ & -0.000 & $H_{K}$ & 7072.116 \\
\hline 5 & 225.856 & $23.754^{\mathrm{a}}$ & $24.150^{\mathrm{a}}$ & $\tau_{\text {aacc }}^{\prime}$ & -0.007 & $\Phi_{\mathrm{abb}}$ & 5.534 & $d_{2}$ & -0.000 & $h_{1}$ & -0.000 \\
\hline 6 & 3052.329 & 8.691 & 9.786 & $\tau_{\mathrm{bbcc}}^{\prime}$ & -0.011 & $\Phi_{\text {aac }}$ & -1515.360 & & & $h_{2}$ & 0.001 \\
\hline 7 & $-3310.921^{a}$ & -8.912 & $6.571^{\mathrm{a}}$ & & & $\Phi_{\text {acc }}$ & -0.059 & & & $h_{3}$ & 0.000 \\
\hline 8 & $336.274^{\mathrm{a}}$ & -12.094 & -0.485 & & & $\Phi_{\mathrm{bcc}}$ & 0.000 & & & & \\
\hline 9 & $-2468.800^{\mathrm{a}}$ & -54.337 & $-24.327^{\mathrm{a}}$ & & & $\Phi_{\mathrm{bbc}}$ & -0.001 & & & & \\
\hline 10 & $3490.356^{\mathrm{a}}$ & $0.795^{\mathrm{a}}$ & -5.110 & & & $\Phi_{\mathrm{abc}}$ & 5.962 & & & & \\
\hline 11 & $403.182^{\mathrm{a}}$ & 2.727 & -6.288 & & & & & & & & \\
\hline 12 & $1278.499^{\mathrm{a}}$ & $-42.247^{\mathrm{a}}$ & -62.886 & & & & & & & & \\
\hline
\end{tabular}

${ }^{a}$ Modes for which Coriolis resonance has been taken into account. 
Table 9. Complete set of non-zero quadratic and cubic force constants for $\mathrm{c}_{-} \mathrm{C}_{3} \mathrm{H}_{3}{ }^{+}$in a symmetry internal coordinate system. See text for more details. Units of force constants are $\mathrm{mdyn} / \AA^{\mathrm{n}} \cdot \mathrm{rad}^{\mathrm{m}}$ appropriate for an energy unit of mdyn $\AA$ ( 1 mdyn $\AA \equiv 1 \mathrm{aJ})$.

\begin{tabular}{|c|c|c|c|c|c|}
\hline \multicolumn{6}{|c|}{ Quadratic and Cubic Force Constants } \\
\hline $\mathrm{F}_{11}$ & 7.217432 & $\mathrm{~F}_{441}=\mathrm{F}_{4 \mathrm{~b} 4 \mathrm{~b} 1}$ & -0.1448 & $\mathrm{~F}_{655}=-\mathrm{F}_{65 \mathrm{~b} 5 \mathrm{~b}}=-\mathrm{F}_{6 \mathrm{~b} 5 \mathrm{~b} 5}$ & -0.4172 \\
\hline $\mathrm{F}_{21}$ & -0.098532 & $\mathrm{~F}_{442}=\mathrm{F}_{4 \mathrm{~b} 4 \mathrm{~b} 2}$ & -19.1998 & $F_{65 b 3}=-F_{6 b 53}$ & 0.3817 \\
\hline $\mathrm{F}_{22}$ & 5.798770 & $\mathrm{~F}_{444}=-\mathrm{F}_{44 \mathrm{~b} 4 \mathrm{~b}}$ & -13.5720 & $\mathrm{~F}_{65 \mathrm{~b} 4 \mathrm{~b}}=\mathrm{F}_{6 \mathrm{~b} 54 \mathrm{~b}}$ & -0.1160 \\
\hline $\mathrm{F}_{33}$ & 0.262156 & $\mathrm{~F}_{541}=\mathrm{F}_{5 \mathrm{~b} 4 \mathrm{~b} 1}$ & 0.2160 & $\mathrm{~F}_{661}=\mathrm{F}_{6 \mathrm{~b} 6 \mathrm{~b} 1}$ & -0.1679 \\
\hline $\mathrm{F}_{44}=\mathrm{F}_{4 \mathrm{~b} 4 \mathrm{~b}}$ & 5.800512 & $\mathrm{~F}_{542}=\mathrm{F}_{5 \mathrm{~b} 4 \mathrm{~b} 2}$ & -0.1399 & $\mathrm{~F}_{662}=\mathrm{F}_{6 \mathrm{~b} 6 \mathrm{~b} 2}$ & -0.0729 \\
\hline $\mathrm{F}_{54}=\mathrm{F}_{5 \mathrm{~b} 4 \mathrm{~b}}$ & -0.009810 & $\mathrm{~F}_{544}=-\mathrm{F}_{54 \mathrm{~b} 4 \mathrm{~b}}=-\mathrm{F}_{5 \mathrm{~b} 44 \mathrm{~b}}$ & -0.0774 & $\mathrm{~F}_{664}=-\mathrm{F}_{6 \mathrm{~b} 64 \mathrm{~b}}=-\mathrm{F}_{6 \mathrm{~b} 6 \mathrm{~b} 4}$ & 0.0495 \\
\hline $\mathrm{F}_{55}=\mathrm{F}_{5 \mathrm{~b} 5 \mathrm{~b}}$ & 5.316006 & $\mathrm{~F}_{54 \mathrm{~b} 3}=-\mathrm{F}_{5 \mathrm{~b} 43}$ & -0.1386 & $\mathrm{~F}_{665}=-\mathrm{F}_{6 \mathrm{~b} 65 \mathrm{~b}}=-\mathrm{F}_{6 \mathrm{~b} 6 \mathrm{~b} 5}$ & -0.2352 \\
\hline $\mathrm{F}_{64}=\mathrm{F}_{6 \mathrm{~b} 4 \mathrm{~b}}$ & 0.017754 & $\mathrm{~F}_{551}=\mathrm{F}_{5 \mathrm{~b} 5 \mathrm{~b} 1}$ & -13.225 & $\mathrm{~F}_{666}=-\mathrm{F}_{6 \mathrm{~b} 6 \mathrm{~b} 6}$ & 0.0959 \\
\hline $\mathrm{F}_{65}=\mathrm{F}_{6 \mathrm{~b} 5 \mathrm{~b}}$ & 0.298226 & $\mathrm{~F}_{552}=\mathrm{F}_{5 \mathrm{~b} 5 \mathrm{~b} 2}$ & -0.2622 & $\mathrm{~F}_{771}$ & -0.2385 \\
\hline $\mathrm{F}_{66}=\mathrm{F}_{6 \mathrm{~b} 6 \mathrm{~b}}$ & 0.414829 & $\mathrm{~F}_{554}=-\mathrm{F}_{5 \mathrm{~b} 54 \mathrm{~b}}=-\mathrm{F}_{5 \mathrm{~b} 5 \mathrm{~b} 4}$ & -0.1110 & $\mathrm{~F}_{772}$ & -0.0827 \\
\hline $\mathrm{F}_{77}$ & 0.371862 & $\mathrm{~F}_{555}=-\mathrm{F}_{5 \mathrm{~b} 5 \mathrm{~b} 5}$ & -18.9961 & $\mathrm{~F}_{874}=\mathrm{F}_{8 \mathrm{~b} 74 \mathrm{~b}}$ & -0.0760 \\
\hline $\mathrm{F}_{88}=\mathrm{F}_{8 \mathrm{~b} 8 \mathrm{~b}}$ & 0.490412 & $\mathrm{~F}_{641}=\mathrm{F}_{6 \mathrm{~b} 4 \mathrm{~b} 1}$ & -0.0146 & $\mathrm{~F}_{875}=\mathrm{F}_{8 \mathrm{~b} 75 \mathrm{~b}}$ & 0.3281 \\
\hline $\mathrm{F}_{111}$ & -22.5615 & $\mathrm{~F}_{642}=\mathrm{F}_{6 \mathrm{~b} 4 \mathrm{~b} 2}$ & -0.0009 & $\mathrm{~F}_{876}=\mathrm{F}_{8 \mathrm{~b} 76 \mathrm{~b}}$ & 0.2836 \\
\hline $\mathrm{F}_{211}$ & -0.1640 & $\mathrm{~F}_{644}=-\mathrm{F}_{64 \mathrm{~b} 4 \mathrm{~b}}=-\mathrm{F}_{6 \mathrm{~b} 4 \mathrm{~b} 4}$ & 0.0073 & $\mathrm{~F}_{881}=\mathrm{F}_{8 \mathrm{~b} 8 \mathrm{~b} 1}$ & -0.4132 \\
\hline $\mathrm{F}_{221}$ & 0.1680 & $F_{64 b 3}=-F_{6 b 43}$ & -0.0602 & $\mathrm{~F}_{882}=\mathrm{F}_{8 \mathrm{~b} 8 \mathrm{~b} 2}$ & -0.1193 \\
\hline $\mathrm{F}_{222}$ & -19.2136 & $\mathrm{~F}_{651}=\mathrm{F}_{6 \mathrm{~b} 5 \mathrm{~b} 1}$ & -0.1032 & $\mathrm{~F}_{884}=-\mathrm{F}_{8 \mathrm{~b} 84 \mathrm{~b}}=-\mathrm{F}_{8 \mathrm{~b} 8 \mathrm{~b} 4}$ & -0.0776 \\
\hline $\mathrm{F}_{331}$ & -0.2589 & $\mathrm{~F}_{652}=\mathrm{F}_{6 \mathrm{~b} 5 \mathrm{~b} 2}$ & -0.1790 & $\mathrm{~F}_{885}=-\mathrm{F}_{8 \mathrm{~b} 85 \mathrm{~b}}=-\mathrm{F}_{8 \mathrm{~b} 8 \mathrm{~b} 5}$ & 0.3106 \\
\hline $\mathrm{F}_{332}$ & -0.0596 & $\mathrm{~F}_{654}=\mathrm{F}_{6 \mathrm{~b} 5 \mathrm{~b} 4}$ & 0.1160 & $\mathrm{~F}_{886}=-\mathrm{F}_{8 \mathrm{~b} 86 \mathrm{~b}}=-\mathrm{F}_{8 \mathrm{~b} 8 \mathrm{~b}}$ & 0.2418 \\
\hline
\end{tabular}


Table 10. Complete set of non-zero quartic force constants for $\mathrm{c}-\mathrm{C}_{3} \mathrm{H}_{3}{ }^{+}$in a symmetry internal coordinate system. See text for more details. Units of force constants are $\mathrm{mdyn} / \AA^{\mathrm{n}} \cdot \mathrm{rad}^{\mathrm{m}}$ appropriate for an energy unit of mdyn $\AA$ ( 1 mdyn $\AA \equiv 1 \mathrm{aJ})$.

\begin{tabular}{|c|c|c|c|c|c|}
\hline \multicolumn{6}{|c|}{ Quartic Force Constants } \\
\hline$\overline{F_{1111}}$ & 59.44 & $\mathrm{~F}_{7744}=\mathrm{F}_{774 \mathrm{~b} 4 \mathrm{~b}}$ & -0.11 & $\mathrm{~F}_{5554}=\mathrm{F}_{5 \mathrm{~b} 5 \mathrm{~b} 5 \mathrm{~b} 4 \mathrm{~b}}=3 \mathrm{~F}_{5 \mathrm{~b} 5 \mathrm{~b} 54}=3 \mathrm{~F}_{5 \mathrm{~b} 554 \mathrm{~b}}$ & -0.50 \\
\hline $\mathrm{F}_{2111}$ & 0.20 & $\mathrm{~F}_{7754}=\mathrm{F}_{775 \mathrm{~b} 4 \mathrm{~b}}$ & -0.04 & $\mathrm{~F}_{6444}=\mathrm{F}_{6 \mathrm{~b} 4 \mathrm{~b} 4 \mathrm{~b} 4 \mathrm{~b}}=3 \mathrm{~F}_{64 \mathrm{~b} 4 \mathrm{~b} 4}=3 \mathrm{~F}_{6 \mathrm{~b} 4 \mathrm{~b} 44}$ & 0.05 \\
\hline $\mathrm{F}_{2211}$ & -0.45 & $\mathrm{~F}_{7755}=\mathrm{F}_{775 \mathrm{~b} 5 \mathrm{~b}}$ & -0.02 & $\mathrm{~F}_{6555}=\mathrm{F}_{6 \mathrm{~b} 5 \mathrm{~b} 5 \mathrm{~b} 5 \mathrm{~b}}=3 \mathrm{~F}_{65 \mathrm{~b} 5 \mathrm{~b} 5}=3 \mathrm{~F}_{6 \mathrm{~b} 5 \mathrm{~b} 55}$ & 0.55 \\
\hline $\mathrm{F}_{2221}$ & -0.35 & $\mathrm{~F}_{7764}=\mathrm{F}_{776 \mathrm{~b} 4 \mathrm{~b}}$ & 0.03 & $\mathrm{~F}_{6664}=\mathrm{F}_{6 \mathrm{~b} 6 \mathrm{~b} 6 \mathrm{~b} 4 \mathrm{~b}}=3 \mathrm{~F}_{6 \mathrm{~b} 6 \mathrm{~b} 64}=3 \mathrm{~F}_{6 \mathrm{~b} 664 \mathrm{~b}}$ & 0.19 \\
\hline $\mathrm{F}_{2222}$ & 56.66 & $\mathrm{~F}_{7765}=\mathrm{F}_{776 \mathrm{~b} 5 \mathrm{~b}}$ & 0.03 & $\mathrm{~F}_{6665}=\mathrm{F}_{6 \mathrm{~b} 6 \mathrm{~b} 6 \mathrm{~b} 5 \mathrm{~b}}=3 \mathrm{~F}_{6 \mathrm{~b} 6 \mathrm{~b} 65}=3 \mathrm{~F}_{6 \mathrm{~b} 665 \mathrm{~b}}$ & 0.19 \\
\hline $\mathrm{F}_{3311}$ & 0.02 & $\mathrm{~F}_{7766}=\mathrm{F}_{776 \mathrm{~b} 6 \mathrm{~b}}$ & 0.94 & $\mathrm{~F}_{5441}=-\mathrm{F}_{54 \mathrm{~b} 4 \mathrm{~b} 1}=-\mathrm{F}_{5 \mathrm{~b} 4 \mathrm{~b} 41}$ & 0.09 \\
\hline $\mathrm{F}_{3321}$ & 0.11 & $\mathrm{~F}_{8741}=\mathrm{F}_{8 \mathrm{~b} 74 \mathrm{~b} 1}$ & 0.15 & $\mathrm{~F}_{5442}=-\mathrm{F}_{54 \mathrm{~b} 4 \mathrm{~b} 2}=-\mathrm{F}_{5 \mathrm{~b} 4 \mathrm{~b} 42}$ & 0.21 \\
\hline $\mathrm{F}_{3322}$ & -0.00 & $\mathrm{~F}_{8742}=\mathrm{F}_{8 \mathrm{~b} 74 \mathrm{~b} 2}$ & -0.09 & $\mathrm{~F}_{54 \mathrm{~b} 43}=\mathrm{F}_{5 \mathrm{~b} 443}=-\mathrm{F}_{5 \mathrm{~b} 4 \mathrm{~b} 4 \mathrm{~b} 3}$ & 0.04 \\
\hline $\mathrm{F}_{3333}$ & 0.04 & $\mathrm{~F}_{8751}=\mathrm{F}_{8 \mathrm{~b} 75 \mathrm{~b} 1}$ & -0.18 & $\mathrm{~F}_{5541}=-\mathrm{F}_{5 \mathrm{~b} 5 \mathrm{~b} 41}=-\mathrm{F}_{5 \mathrm{~b} 54 \mathrm{~b} 1}$ & 0.14 \\
\hline $\mathrm{F}_{7711}$ & -0.11 & $\mathrm{~F}_{8752}=\mathrm{F}_{8 \mathrm{~b} 75 \mathrm{~b} 2}$ & -0.10 & $\mathrm{~F}_{5542}=-\mathrm{F}_{5 \mathrm{~b} 5 \mathrm{~b} 42}=-\mathrm{F}_{5 \mathrm{~b} 542}$ & 0.02 \\
\hline $\mathrm{F}_{7721}$ & 0.15 & $\mathrm{~F}_{8761}=\mathrm{F}_{8 \mathrm{~b} 76 \mathrm{~b} 1}$ & -0.11 & $\mathrm{~F}_{554 \mathrm{~b} 3}=\mathrm{F}_{5 \mathrm{~b} 543}=-\mathrm{F}_{5 \mathrm{~b} 5 \mathrm{~b} 4 \mathrm{~b} 3}$ & 0.28 \\
\hline $\mathrm{F}_{7722}$ & -0.10 & $\mathrm{~F}_{8762}=\mathrm{F}_{8 \mathrm{~b} 76 \mathrm{~b} 2}$ & -0.08 & $\mathrm{~F}_{6441}=-\mathrm{F}_{64 \mathrm{~b} 4 \mathrm{~b} 1}=-\mathrm{F}_{6 \mathrm{~b} 4 \mathrm{~b} 41}$ & -0.01 \\
\hline $\mathrm{F}_{7733}$ & 0.67 & $\mathrm{~F}_{8811}=\mathrm{F}_{8 \mathrm{~b} 8 \mathrm{~b} 11}$ & -0.08 & $\mathrm{~F}_{6442}=-\mathrm{F}_{64 \mathrm{~b} 4 \mathrm{~b} 2}=-\mathrm{F}_{6 \mathrm{~b} 4 \mathrm{~b} 42}$ & 0.03 \\
\hline $\mathrm{F}_{774 \mathrm{~b} 3}$ & -0.02 & $\mathrm{~F}_{8821}=\mathrm{F}_{8 \mathrm{~b} 8 \mathrm{~b} 21}$ & 0.26 & $\mathrm{~F}_{64 \mathrm{~b} 43}=\mathrm{F}_{6 \mathrm{~b} 443}=-\mathrm{F}_{6 \mathrm{~b} 4 \mathrm{~b} 4 \mathrm{~b} 3}$ & 0.05 \\
\hline $\mathrm{F}_{775 \mathrm{~b} 3}$ & 0.01 & $\mathrm{~F}_{8822}=\mathrm{F}_{8 \mathrm{~b} 8 \mathrm{~b} 22}$ & -0.11 & $\mathrm{~F}_{6551}=-\mathrm{F}_{65 \mathrm{~b} 5 \mathrm{~b} 1}=-\mathrm{F}_{6 \mathrm{~b} 5 \mathrm{~b} 51}$ & -0.10 \\
\hline $\mathrm{F}_{776 \mathrm{~b} 3}$ & 0.04 & $\mathrm{~F}_{8833}=\mathrm{F}_{8 \mathrm{~b} 8 \mathrm{~b} 33}$ & 0.62 & $\mathrm{~F}_{6552}=-\mathrm{F}_{65 \mathrm{~b} 5 \mathrm{~b} 2}=-\mathrm{F}_{6 \mathrm{~b} 5 \mathrm{~b} 52}$ & 0.26 \\
\hline $\mathrm{F}_{7777}$ & 0.09 & $\mathrm{~F}_{8844}=\mathrm{F}_{8 \mathrm{~b} 8 \mathrm{~b} 4 \mathrm{~b} 4 \mathrm{~b}}$ & -0.14 & $\mathrm{~F}_{65 \mathrm{~b} 53}=\mathrm{F}_{6 \mathrm{~b} 553}=-\mathrm{F}_{6 \mathrm{~b} 5 \mathrm{~b} 5 \mathrm{~b} 3}$ & 0.24 \\
\hline $\mathrm{F}_{4411}=\mathrm{F}_{4 \mathrm{~b} 4 \mathrm{~b} 11}$ & -0.37 & $\mathrm{~F}_{884 \mathrm{~b} 4 \mathrm{~b}}=\mathrm{F}_{8 \mathrm{~b} 8 \mathrm{~b} 44}$ & -0.01 & $\mathrm{~F}_{6641}=-\mathrm{F}_{6 \mathrm{~b} 6 \mathrm{~b} 41}=-\mathrm{F}_{6 \mathrm{~b} 64 \mathrm{~b} 1}$ & -0.04 \\
\hline $\mathrm{F}_{4421}=\mathrm{F}_{4 \mathrm{~b} 4 \mathrm{~b} 21}$ & -0.42 & $\mathrm{~F}_{8854}=\mathrm{F}_{8 \mathrm{~b} 8 \mathrm{~b} 5 \mathrm{~b} 4 \mathrm{~b}}$ & 0.03 & $\mathrm{~F}_{6642}=-\mathrm{F}_{6 \mathrm{~b} 6 \mathrm{~b} 42}=-\mathrm{F}_{6 \mathrm{~b} 64 \mathrm{~b} 2}$ & 0.11 \\
\hline $\mathrm{F}_{4422}=\mathrm{F}_{4 \mathrm{~b} 4 \mathrm{~b} 22}$ & 56.74 & $\mathrm{~F}_{8855}=\mathrm{F}_{8 \mathrm{~b} 8 \mathrm{~b} 5 \mathrm{~b} 5 \mathrm{~b}}$ & -0.45 & $\mathrm{~F}_{664 \mathrm{~b} 3}=\mathrm{F}_{6 \mathrm{~b} 643}=-\mathrm{F}_{6 \mathrm{~b} 6 \mathrm{~b} 4 \mathrm{~b} 3}$ & -0.02 \\
\hline $\mathrm{F}_{4433}=\mathrm{F}_{4 \mathrm{~b} 4 \mathrm{~b} 33}$ & -0.00 & $\mathrm{~F}_{885 \mathrm{~b} 4 \mathrm{~b}}=\mathrm{F}_{8 \mathrm{~b} 8 \mathrm{~b} 54}$ & -0.11 & $\mathrm{~F}_{6651}=-\mathrm{F}_{6 \mathrm{~b} 6 \mathrm{~b} 51}=-\mathrm{F}_{6 \mathrm{~b} 65 \mathrm{~b} 1}$ & 0.01 \\
\hline $\mathrm{F}_{5411}=\mathrm{F}_{5 \mathrm{~b} 4 \mathrm{~b} 11}$ & -0.26 & $F_{885 b 5 b}=F_{8 b 8 b 55}$ & 0.55 & $\mathrm{~F}_{6652}=-\mathrm{F}_{6 \mathrm{~b} 6 \mathrm{~b} 52}=-\mathrm{F}_{6 \mathrm{~b} 65 \mathrm{~b} 2}$ & 0.06 \\
\hline $\mathrm{F}_{5421}=\mathrm{F}_{5 \mathrm{~b} 4 \mathrm{~b} 21}$ & 0.18 & $\mathrm{~F}_{8864}=\mathrm{F}_{8 \mathrm{~b} 8 \mathrm{~b} 6 \mathrm{~b} 4 \mathrm{~b}}$ & -0.03 & $\mathrm{~F}_{665 \mathrm{~b} 3}=\mathrm{F}_{6 \mathrm{~b} 653}=-\mathrm{F}_{6 \mathrm{~b} 6 \mathrm{~b} 5 \mathrm{~b} 3}$ & 0.08 \\
\hline $\mathrm{F}_{5422}=\mathrm{F}_{5 \mathrm{~b} 4 \mathrm{~b} 22}$ & 0.35 & $\mathrm{~F}_{8865}=\mathrm{F}_{8 \mathrm{~b} 8 \mathrm{~b} 6 \mathrm{~b} 5 \mathrm{~b}}$ & -0.20 & $\mathrm{~F}_{8744}=-\mathrm{F}_{874 \mathrm{~b} 4 \mathrm{~b}}=-\mathrm{F}_{8 \mathrm{~b} 74 \mathrm{~b} 4}$ & -0.05 \\
\hline $\mathrm{F}_{5433}=\mathrm{F}_{5 \mathrm{~b} 4 \mathrm{~b} 33}$ & -0.02 & $\mathrm{~F}_{8866}=\mathrm{F}_{8 \mathrm{~b} 8 \mathrm{~b} 6 \mathrm{~b} 6 \mathrm{~b}}$ & 0.43 & $\mathrm{~F}_{8755}=-\mathrm{F}_{875 \mathrm{~b} 5 \mathrm{~b}}=-\mathrm{F}_{8 \mathrm{~b} 75 \mathrm{~b} 5}$ & -0.76 \\
\hline $\mathrm{F}_{5511}=\mathrm{F}_{5 \mathrm{~b} 5 \mathrm{~b} 11}$ & 20.59 & $\mathrm{~F}_{886 \mathrm{~b} 4 \mathrm{~b}}=\mathrm{F}_{8 \mathrm{~b} 8 \mathrm{~b} 64}$ & -0.00 & $\mathrm{~F}_{8766}=-\mathrm{F}_{876 \mathrm{~b} 6 \mathrm{~b}}=-\mathrm{F}_{8 \mathrm{~b} 76 \mathrm{~b} 6}$ & -0.68 \\
\hline $\mathrm{F}_{5521}=\mathrm{F}_{5 \mathrm{~b} 5 \mathrm{~b} 21}$ & 0.50 & $F_{886 b 5 b}=F_{8 b 8 b 65}$ & 0.22 & $\mathrm{~F}_{8841}=-\mathrm{F}_{8 \mathrm{~b} 84 \mathrm{~b} 1}=-\mathrm{F}_{8 \mathrm{~b} 8 \mathrm{~b} 41}$ & 0.12 \\
\hline $\mathrm{F}_{5522}=\mathrm{F}_{5 \mathrm{~b} 5 \mathrm{~b} 22}$ & -0.34 & $\mathrm{~F}_{886 \mathrm{~b} 6 \mathrm{~b}}=\mathrm{F}_{8 \mathrm{~b} 8 \mathrm{~b} 66}$ & 1.39 & $\mathrm{~F}_{8842}=-\mathrm{F}_{8 \mathrm{~b} 84 \mathrm{~b} 2}=-\mathrm{F}_{8 \mathrm{~b} 8 \mathrm{~b} 42}$ & -0.06 \\
\hline $\mathrm{F}_{5533}=\mathrm{F}_{5 \mathrm{~b} 5 \mathrm{~b} 33}$ & -0.14 & $\mathrm{~F}_{8877}=\mathrm{F}_{8 \mathrm{~b} 8 \mathrm{~b} 77}$ & 0.47 & $\mathrm{~F}_{884 \mathrm{~b} 3}=\mathrm{F}_{8 \mathrm{~b} 843}=-\mathrm{F}_{8 \mathrm{~b} 8 \mathrm{~b} 4 \mathrm{~b} 3}$ & -0.03 \\
\hline $\mathrm{F}_{5544}=\mathrm{F}_{5 \mathrm{~b} 5 \mathrm{~b} 44}$ & -0.33 & $F_{4441}=-F_{4 b 4 b 41}$ & -0.30 & $\mathrm{~F}_{8851}=-\mathrm{F}_{8 \mathrm{~b} 85 \mathrm{~b} 1}=-\mathrm{F}_{8 \mathrm{~b} 8 \mathrm{~b} 51}$ & -0.41 \\
\hline $\mathrm{F}_{554 \mathrm{~b} 4 \mathrm{~b}}=\mathrm{F}_{5 \mathrm{~b} 5 \mathrm{~b} 4 \mathrm{~b} 4 \mathrm{~b}}$ & -0.34 & $\mathrm{~F}_{4442}=-\mathrm{F}_{4 \mathrm{~b} 4 \mathrm{~b} 42}$ & 40.12 & $\mathrm{~F}_{8852}=-\mathrm{F}_{8 \mathrm{~b} 85 \mathrm{~b} 2}=-\mathrm{F}_{8 \mathrm{~b} 8 \mathrm{~b} 52}$ & -0.40 \\
\hline $\mathrm{F}_{6411}=\mathrm{F}_{6 \mathrm{~b} 4 \mathrm{~b} 11}$ & 0.05 & $F_{4 b 443}=-F_{4 b 4 b 4 b 3}$ & 0.00 & $\mathrm{~F}_{885 \mathrm{~b} 3}=\mathrm{F}_{8 \mathrm{~b} 853}=-\mathrm{F}_{8 \mathrm{~b} 8 \mathrm{~b} 5 \mathrm{~b} 3}$ & -0.22 \\
\hline $\mathrm{F}_{6421}=\mathrm{F}_{6 \mathrm{~b} 4 \mathrm{~b} 21}$ & 0.02 & $\mathrm{~F}_{54 \mathrm{~b} 31}=-\mathrm{F}_{5 \mathrm{~b} 431}$ & 0.14 & $\mathrm{~F}_{8861}=-\mathrm{F}_{8 \mathrm{~b} 86 \mathrm{~b} 1}=-\mathrm{F}_{8 \mathrm{~b} 8 \mathrm{~b} 61}$ & -0.02 \\
\hline$F_{6422}=F_{6 b 4 b 22}$ & 0.05 & $\mathrm{~F}_{54 \mathrm{~b} 32}=-\mathrm{F}_{5 \mathrm{~b} 432}$ & -0.08 & $\mathrm{~F}_{8862}=-\mathrm{F}_{8 \mathrm{~b} 86 \mathrm{~b} 2}=-\mathrm{F}_{8 \mathrm{~b} 8 \mathrm{~b} 62}$ & -0.09 \\
\hline$F_{6433}=F_{6 b 4 b 33}$ & 0.01 & $\mathrm{~F}_{5551}=-\mathrm{F}_{5 \mathrm{~b} 5 \mathrm{~b} 51}$ & 38.85 & $\mathrm{~F}_{886 \mathrm{~b} 3}=\mathrm{F}_{8 \mathrm{~b} 863}=-\mathrm{F}_{8 \mathrm{~b} 8 \mathrm{~b} 6 \mathrm{~b} 3}$ & -0.53 \\
\hline $\mathrm{F}_{6511}=\mathrm{F}_{6 \mathrm{~b} 5 \mathrm{~b} 11}$ & -0.22 & $\mathrm{~F}_{5552}=-\mathrm{F}_{5 \mathrm{~b} 5 \mathrm{~b} 52}$ & 0.06 & $\mathrm{~F}_{6541}=-\mathrm{F}_{65 \mathrm{~b} 4 \mathrm{~b} 1}=-\mathrm{F}_{6 \mathrm{~b} 54 \mathrm{bl}}=-\mathrm{F}_{6 \mathrm{~b} 5 \mathrm{~b} 41}$ & -0.06 \\
\hline $\mathrm{F}_{6521}=\mathrm{F}_{6 \mathrm{~b} 5 \mathrm{~b} 21}$ & 0.03 & $\mathrm{~F}_{5 \mathrm{~b} 553}=-\mathrm{F}_{5 \mathrm{~b} 5 \mathrm{~b} 5 \mathrm{~b} 3}$ & -0.18 & $F_{6542}=-F_{65 b 4 b 2}=-F_{6 b 54 b 2}=-F_{6 b 5 b 42}$ & 0.07 \\
\hline $\mathrm{F}_{6522}=\mathrm{F}_{6 \mathrm{~b} 5 \mathrm{~b} 22}$ & -0.16 & $\mathrm{~F}_{64 \mathrm{~b} 31}=-\mathrm{F}_{6 \mathrm{~b} 431}$ & 0.10 & $\mathrm{~F}_{654 \mathrm{~b} 3}=\mathrm{F}_{65 \mathrm{~b} 43}=\mathrm{F}_{6 \mathrm{~b} 543}=-\mathrm{F}_{6 \mathrm{~b} 5 \mathrm{~b} 4 \mathrm{~b} 3}$ & 0.08 \\
\hline $\mathrm{F}_{6533}=\mathrm{F}_{6 \mathrm{~b} 5 \mathrm{~b} 33}$ & 0.04 & $\mathrm{~F}_{64 \mathrm{~b} 32}=-\mathrm{F}_{6 \mathrm{~b} 432}$ & -0.03 & $\mathrm{~F}_{8754}=-\mathrm{F}_{875 \mathrm{~b} 4 \mathrm{~b}}=-\mathrm{F}_{8 \mathrm{~b} 754 \mathrm{~b}}=-\mathrm{F}_{8 \mathrm{~b} 75 \mathrm{~b} 4}$ & 0.02 \\
\hline $\mathrm{F}_{6544}=\mathrm{F}_{6 \mathrm{~b} 5 \mathrm{~b} 4 \mathrm{~b} 4 \mathrm{~b}}$ & -0.10 & $\mathrm{~F}_{65 \mathrm{~b} 31}=-\mathrm{F}_{6 \mathrm{~b} 531}$ & -0.06 & $F_{8764}=-F_{876 b 4 b}=-F_{8 b 764 b}=-F_{8 b 76 b 4}$ & 0.03 \\
\hline $\mathrm{F}_{654 \mathrm{~b} 4 \mathrm{~b}}=\mathrm{F}_{6 \mathrm{~b} 5 \mathrm{~b} 44}$ & -0.13 & $\mathrm{~F}_{65 \mathrm{~b} 32}=-\mathrm{F}_{6 \mathrm{~b} 532}$ & -0.12 & $\mathrm{~F}_{8765}=-\mathrm{F}_{876 \mathrm{~b} 5 \mathrm{~b}}=-\mathrm{F}_{8765 \mathrm{~b}}=-\mathrm{F}_{8 \mathrm{~b} 76 \mathrm{~b} 5}$ & -0.68 \\
\hline $\mathrm{F}_{6554}=\mathrm{F}_{6 \mathrm{~b} 5 \mathrm{~b} 5 \mathrm{~b} 4 \mathrm{~b}}$ & -0.13 & $\mathrm{~F}_{6661}=-\mathrm{F}_{6 \mathrm{~b} 6 \mathrm{~b} 61}$ & 0.06 & 12 Non-Symmetry-Unique Constants: & \\
\hline $\mathrm{F}_{65 \mathrm{~b} 5 \mathrm{~b} 4}=\mathrm{F}_{6 \mathrm{~b} 554 \mathrm{~b}}$ & 0.05 & $\mathrm{~F}_{6662}=-\mathrm{F}_{6 \mathrm{~b} 6 \mathrm{~b} 62}$ & -0.08 & $\mathrm{~F}_{7654}=\left(\mathrm{F}_{6644}-\mathrm{F}_{6655}\right) / 2$ & 0.00 \\
\hline $\mathrm{F}_{6611}=\mathrm{F}_{6 \mathrm{~b} 6 \mathrm{~b} 11}$ & 0.03 & $\mathrm{~F}_{6 \mathrm{~b} 663}=-\mathrm{F}_{6 \mathrm{~b} 6 \mathrm{~b} 6 \mathrm{~b} 3}$ & 0.01 & $\mathrm{~F}_{9854}=\left(\mathrm{F}_{8844}-\mathrm{F}_{8855}\right) / 2$ & 0.01 \\
\hline
\end{tabular}




\begin{tabular}{|c|c|c|c|c|c|}
\hline $\mathrm{F}_{6621}=\mathrm{F}_{6 \mathrm{~b} 6 \mathrm{~b} 21}$ & 0.24 & $\mathrm{~F}_{874 \mathrm{~b} 3}=-\mathrm{F}_{8 \mathrm{~b} 743}$ & -0.04 & $\mathrm{~F}_{9876}=\left(\mathrm{F}_{8866}-\mathrm{F}_{8877}\right) / 2$ & 0.00 \\
\hline $\mathrm{F}_{6622}=\mathrm{F}_{6 \mathrm{~b} 6 \mathrm{~b} 22}$ & -0.11 & $\mathrm{~F}_{875 \mathrm{~b} 3}=-\mathrm{F}_{8 \mathrm{~b} 753}$ & -0.11 & $\mathrm{~F}_{65 \mathrm{~b} 4 \mathrm{~b} 4}=\mathrm{F}_{6 \mathrm{~b} 54 \mathrm{~b} 4}=\left(\mathrm{F}_{6544}-\mathrm{F}_{654 \mathrm{~b} 4 \mathrm{~b}}\right) / 2$ & 0.02 \\
\hline $\mathrm{F}_{6633}=\mathrm{F}_{6 \mathrm{~b} 6 \mathrm{~b} 33}$ & 0.09 & $\mathrm{~F}_{876 \mathrm{~b} 3}=-\mathrm{F}_{8 \mathrm{~b} 763}$ & -0.79 & $F_{65 b 54 b}=F_{6 b 5 b 54}=\left(F_{6554}-F_{65 b 5 b 4}\right) / 2$ & -0.09 \\
\hline $\mathrm{F}_{6644}=\mathrm{F}_{6 \mathrm{~b} 6 \mathrm{~b} 4 \mathrm{~b} 4 \mathrm{~b}}$ & -0.09 & $\mathrm{~F}_{8887}=-\mathrm{F}_{8 \mathrm{~b} 8 \mathrm{~b} 87}$ & 0.57 & $\mathrm{~F}_{6 \mathrm{~b} 65 \mathrm{~b} 4}=\mathrm{F}_{6 \mathrm{~b} 654 \mathrm{~b}}=\left(\mathrm{F}_{6654}-\mathrm{F}_{665 \mathrm{~b} 4 \mathrm{~b}}\right) / 2$ & 0.06 \\
\hline $\mathrm{F}_{664 \mathrm{~b} 4 \mathrm{~b}}=\mathrm{F}_{6 \mathrm{~b} 6 \mathrm{~b} 44}$ & -0.12 & $\mathrm{~F}_{4444}=\mathrm{F}_{4 \mathrm{~b} 4 \mathrm{~b} 4 \mathrm{~b} 4 \mathrm{~b}}=3 \mathrm{~F}_{4 \mathrm{~b} 4 \mathrm{~b} 44}$ & 85.18 & $\mathrm{~F}_{8 \mathrm{~b} 84 \mathrm{~b} 4}=\left(\mathrm{F}_{8844}-\mathrm{F}_{884 \mathrm{~b} 4 \mathrm{~b}}\right) / 2$ & -0.07 \\
\hline $\mathrm{F}_{6654}=\mathrm{F}_{6 \mathrm{~b} 6 \mathrm{~b} 5 \mathrm{~b} 4 \mathrm{~b}}$ & -0.02 & $\mathrm{~F}_{5555}=\mathrm{F}_{5 \mathrm{~b} 5 \mathrm{~b} 5 \mathrm{~b} 5 \mathrm{~b}}=3 \mathrm{~F}_{5 \mathrm{~b} 5 \mathrm{~b} 55}$ & 92.62 & $\mathrm{~F}_{8 \mathrm{~b} 85 \mathrm{~b} 5}=\left(\mathrm{F}_{8855}-\mathrm{F}_{885 \mathrm{~b} 5 \mathrm{~b}}\right) / 2$ & -0.50 \\
\hline $\mathrm{F}_{6655}=\mathrm{F}_{6 \mathrm{~b} 6 \mathrm{~b} 5 \mathrm{~b} 5 \mathrm{~b}}$ & 0.07 & $\mathrm{~F}_{6666}=\mathrm{F}_{6 \mathrm{~b} 6 \mathrm{~b} 6 \mathrm{~b} 6 \mathrm{~b}}=3 \mathrm{~F}_{6 \mathrm{~b} 6 \mathrm{~b} 66}$ & -0.16 & $\mathrm{~F}_{8 \mathrm{~b} 86 \mathrm{~b} 6}=\left(\mathrm{F}_{8866}-\mathrm{F}_{886 \mathrm{~b} 6 \mathrm{~b}}\right) / 2$ & -0.48 \\
\hline $\mathrm{F}_{665 \mathrm{~b} 4 \mathrm{~b}}=\mathrm{F}_{6 \mathrm{~b} 6 \mathrm{~b} 54}$ & -0.14 & $\mathrm{~F}_{8888}=\mathrm{F}_{8 \mathrm{~b} 8 \mathrm{~b} 8 \mathrm{~b} 8 \mathrm{~b}}=3 \mathrm{~F}_{8 \mathrm{~b} 8 \mathrm{~b} 88}$ & 0.43 & $\mathrm{~F}_{8 \mathrm{~b} 854 \mathrm{~b}}=\mathrm{F}_{8 \mathrm{~b} 85 \mathrm{~b} 4}=\left(\mathrm{F}_{8854}-\mathrm{F}_{885 \mathrm{~b} 4 \mathrm{~b}}\right) / 2$ & 0.07 \\
\hline $\mathrm{F}_{665 \mathrm{~b} 5 \mathrm{~b}}=\mathrm{F}_{6 \mathrm{~b} 6 \mathrm{~b} 55}$ & 0.06 & $\mathrm{~F}_{5444}=\mathrm{F}_{5 \mathrm{~b} 4 \mathrm{~b} 4 \mathrm{~b} 4 \mathrm{~b}}=3 \mathrm{~F}_{5 \mathrm{~b} 4 \mathrm{~b} 44}=3 \mathrm{~F}_{54 \mathrm{~b} 4 \mathrm{~b} 4}$ & 0.55 & $\mathrm{~F}_{8 \mathrm{~b} 864 \mathrm{~b}}=\mathrm{F}_{8 \mathrm{~b} 86 \mathrm{~b} 4}=\left(\mathrm{F}_{8864}-\mathrm{F}_{886 \mathrm{~b} 4 \mathrm{~b}}\right) / 2$ & -0.01 \\
\hline & & & & $\mathrm{F}_{8 \mathrm{~b} 865 \mathrm{~b}}=\mathrm{F}_{8 \mathrm{~b} 86 \mathrm{~b} 5}=\left(\mathrm{F}_{8865}-\mathrm{F}_{886 \mathrm{bb} \mathrm{b}}\right) / 2$ & -0.21 \\
\hline
\end{tabular}


Table 11. Complete set of non-zero quadratic and cubic force constants for $1-\mathrm{C}_{3} \mathrm{H}_{3}{ }^{+}$in a symmetry internal coordinate system. See text for more details. Units of force constants are $\operatorname{mdyn} / \AA^{\mathrm{n}} \cdot \mathrm{rad}^{\mathrm{m}}$ appropriate for an energy unit of mdyn $\AA$ ( 1 mdyn $\left.\AA \equiv 1 \mathrm{aJ}\right)$. x/y/z represent the $10^{\text {th }}, 11^{\text {th }}$, and $12^{\text {th }}$ internal coordinates, respectively.

\begin{tabular}{|c|c|c|c|c|c|c|c|c|c|c|c|}
\hline $\mathrm{F}_{11}$ & 6.029788 & $\mathrm{~F}_{\mathrm{xx}}$ & 0.167448 & $\mathrm{~F}_{444}$ & 15.2311 & $\mathrm{~F}_{765}$ & -0.0249 & $F_{965}$ & 0.0962 & $\mathrm{~F}_{\mathrm{yx} 5}$ & -0.0131 \\
\hline $\mathrm{F}_{21}$ & 0.005712 & $F_{y x}$ & 0.000441 & $\mathrm{~F}_{511}$ & 0.0002 & $\mathrm{~F}_{771}$ & -0.0363 & $F_{971}$ & 0.0092 & $F_{y y 1}$ & -0.1937 \\
\hline $\mathrm{F}_{22}$ & 5.540738 & $\mathrm{~F}_{\mathrm{yy}}$ & 0.385229 & $\mathrm{~F}_{521}$ & 0.0047 & $\mathrm{~F}_{772}$ & 0.0272 & $F_{972}$ & 0.0408 & $F_{y y 2}$ & -0.0120 \\
\hline $\mathrm{F}_{31}$ & -0.119775 & $\mathrm{~F}_{\mathrm{zx}}$ & 0.000222 & $\mathrm{~F}_{522}$ & -0.1527 & $\mathrm{~F}_{773}$ & -0.9361 & $\mathrm{~F}_{973}$ & 0.1397 & $F_{\mathrm{yy} 3}$ & -0.4253 \\
\hline $\mathrm{F}_{32}$ & 0.072319 & $F_{z y}$ & 0.015043 & $\mathrm{~F}_{531}$ & -0.0050 & $\mathrm{~F}_{774}$ & 0.1170 & $\mathrm{~F}_{974}$ & -0.0580 & $F_{y y 4}$ & 0.1286 \\
\hline $\mathrm{F}_{33}$ & 11.885630 & $\mathrm{~F}_{\mathrm{zz}}$ & 0.238988 & $\mathrm{~F}_{532}$ & 0.1349 & $\mathrm{~F}_{775}$ & 0.0325 & $F_{975}$ & -0.0546 & $\mathrm{~F}_{\mathrm{yy} 5}$ & 0.0064 \\
\hline $\mathrm{F}_{41}$ & 0.144706 & $\mathrm{~F}_{111}$ & -34.5269 & $\mathrm{~F}_{533}$ & 0.0086 & $\mathrm{~F}_{861}$ & 0.0002 & $F_{981}$ & 0.0010 & $\mathrm{~F}_{\mathrm{zx} 1}$ & -0.0026 \\
\hline $\mathrm{F}_{42}$ & 0.074156 & $\mathrm{~F}_{211}$ & -0.0010 & $\mathrm{~F}_{541}$ & -0.0043 & $\mathrm{~F}_{862}$ & -0.0015 & $\mathrm{~F}_{982}$ & 0.0095 & $\mathrm{~F}_{\mathrm{zx} 2}$ & -0.0063 \\
\hline $\mathrm{F}_{43}$ & -2.970851 & $\mathrm{~F}_{221}$ & -0.0055 & $\mathrm{~F}_{542}$ & 0.1028 & $\mathrm{~F}_{863}$ & 0.0073 & $F_{983}$ & -0.0528 & $\mathrm{~F}_{\mathrm{zx} 3}$ & -0.0961 \\
\hline $\mathrm{F}_{44}$ & 10.906522 & $\mathrm{~F}_{222}$ & -22.3363 & $\mathrm{~F}_{543}$ & 0.1047 & $\mathrm{~F}_{864}$ & 0.0128 & $\mathrm{~F}_{984}$ & 0.0503 & $\mathrm{~F}_{\mathrm{zx} 4}$ & 0.0867 \\
\hline $\mathrm{F}_{51}$ & 0.001714 & $\mathrm{~F}_{311}$ & 0.1236 & $\mathrm{~F}_{544}$ & 0.2391 & $\mathrm{~F}_{865}$ & -0.0053 & $\mathrm{~F}_{985}$ & -0.0134 & $\mathrm{~F}_{\mathrm{zx} 5}$ & 0.0082 \\
\hline $\mathrm{F}_{52}$ & 0.065407 & $\mathrm{~F}_{321}$ & 0.0056 & $\mathrm{~F}_{551}$ & 0.0024 & $\mathrm{~F}_{871}$ & -0.0002 & $\mathrm{~F}_{991}$ & 0.0086 & $\mathrm{~F}_{\mathrm{zy} 1}$ & -0.0032 \\
\hline $\mathrm{F}_{53}$ & -0.231773 & $\mathrm{~F}_{322}$ & 0.0869 & $\mathrm{~F}_{552}$ & -0.3928 & $\mathrm{~F}_{872}$ & -0.0025 & $\mathrm{~F}_{992}$ & -0.2028 & $\mathrm{~F}_{\mathrm{zy} 2}$ & -0.0007 \\
\hline $\mathrm{F}_{54}$ & -0.173960 & $\mathrm{~F}_{331}$ & -0.0602 & $\mathrm{~F}_{553}$ & -0.1270 & $\mathrm{~F}_{873}$ & 0.1851 & $\mathrm{~F}_{993}$ & -0.1762 & $\mathrm{~F}_{\mathrm{zy} 3}$ & 0.0332 \\
\hline $\mathrm{F}_{55}$ & 0.682966 & $\mathrm{~F}_{332}$ & -0.1223 & $\mathrm{~F}_{554}$ & -0.0076 & $\mathrm{~F}_{874}$ & -0.2203 & $\mathrm{~F}_{994}$ & 0.0320 & $\mathrm{~F}_{\mathrm{zy} 4}$ & -0.0053 \\
\hline $\mathrm{F}_{66}$ & 5.533706 & $\mathrm{~F}_{333}$ & -48.6285 & $\mathrm{~F}_{555}$ & -0.2658 & $\mathrm{~F}_{875}$ & 0.0052 & $\mathrm{~F}_{995}$ & 0.3241 & $\mathrm{~F}_{\mathrm{zy} 5}$ & 0.0068 \\
\hline $\mathrm{F}_{76}$ & -0.002072 & $\mathrm{~F}_{411}$ & -0.1359 & $\mathrm{~F}_{661}$ & -0.0068 & $\mathrm{~F}_{881}$ & -0.1404 & $\mathrm{~F}_{\mathrm{xx} 1}$ & -0.0281 & $\mathrm{~F}_{\mathrm{zz} 1}$ & -0.0031 \\
\hline $\mathrm{F}_{77}$ & 0.283223 & $\mathrm{~F}_{421}$ & -0.0008 & $\mathrm{~F}_{662}$ & -22.4743 & $\mathrm{~F}_{882}$ & -0.0192 & $F_{x x 2}$ & -0.0185 & $\mathrm{~F}_{\mathrm{zz} 2}$ & -0.0768 \\
\hline $\mathrm{F}_{86}$ & -0.004390 & $\mathrm{~F}_{422}$ & 0.1801 & $\mathrm{~F}_{663}$ & 0.1739 & $\mathrm{~F}_{883}$ & -0.6080 & $F_{x \times 3}$ & -0.3280 & $\mathrm{~F}_{\mathrm{zz} 3}$ & -0.2289 \\
\hline $\mathrm{F}_{87}$ & 0.109569 & $\mathrm{~F}_{431}$ & 0.0147 & $\mathrm{~F}_{664}$ & 0.3239 & $\mathrm{~F}_{884}$ & 0.7960 & $F_{x x 4}$ & -0.0273 & $\mathrm{~F}_{\mathrm{zz} 4}$ & -0.0271 \\
\hline $\mathrm{F}_{88}$ & 0.227801 & $\mathrm{~F}_{432}$ & -0.2336 & $\mathrm{~F}_{665}$ & 0.2737 & $\mathrm{~F}_{885}$ & -0.0047 & $F_{x x 5}$ & 0.0040 & $\mathrm{~F}_{\mathrm{zz} 5}$ & 0.4596 \\
\hline $\mathrm{F}_{96}$ & 0.109515 & $\mathrm{~F}_{433}$ & 13.1266 & $\mathrm{~F}_{761}$ & -0.0003 & $\mathrm{~F}_{961}$ & -0.0011 & $\mathrm{~F}_{\mathrm{yx} 1}$ & 0.0022 & & \\
\hline $\mathrm{F}_{97}$ & -0.067911 & $\mathrm{~F}_{441}$ & 0.0753 & $\mathrm{~F}_{762}$ & -0.0023 & $\mathrm{~F}_{962}$ & 0.0428 & $F_{\mathrm{yx} 2}$ & 0.0098 & & \\
\hline $\mathrm{F}_{98}$ & -0.023718 & $\mathrm{~F}_{442}$ & -0.5212 & $\mathrm{~F}_{763}$ & 0.0911 & $\mathrm{~F}_{963}$ & -0.2622 & $\mathrm{~F}_{\mathrm{yx} 3}$ & 0.1577 & & \\
\hline $\mathrm{F}_{99}$ & 0.514243 & $\mathrm{~F}_{443}$ & -45.3965 & $\mathrm{~F}_{764}$ & 0.0117 & $\mathrm{~F}_{964}$ & -0.3053 & $\mathrm{~F}_{\mathrm{yx} 4}$ & 0.0810 & & \\
\hline
\end{tabular}




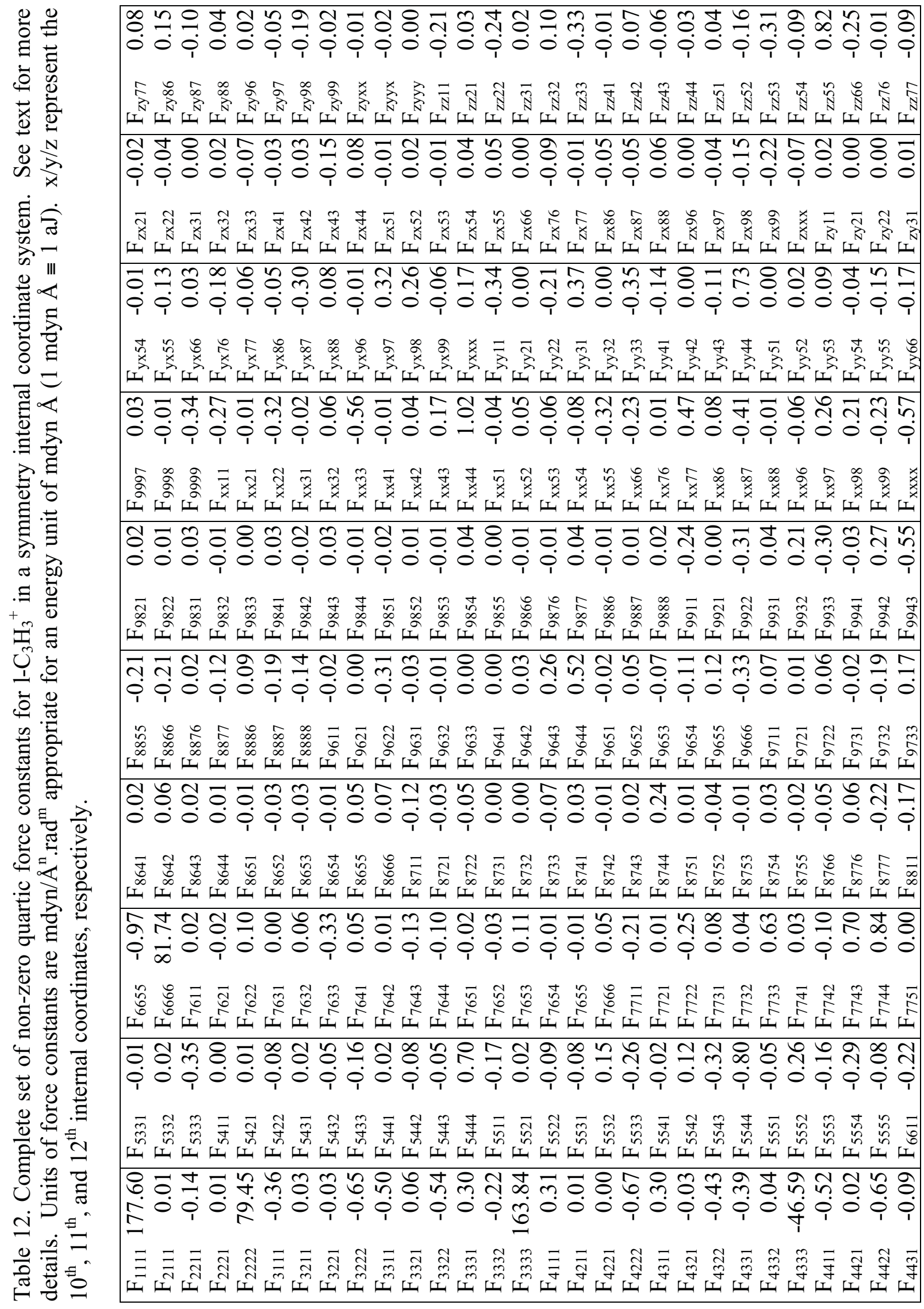




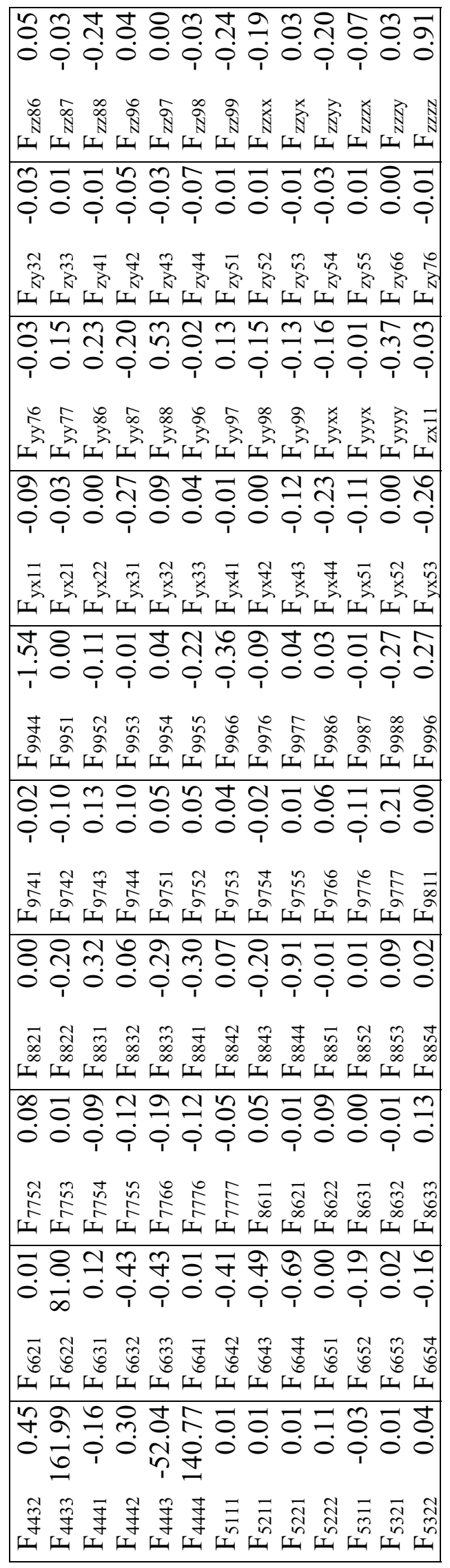




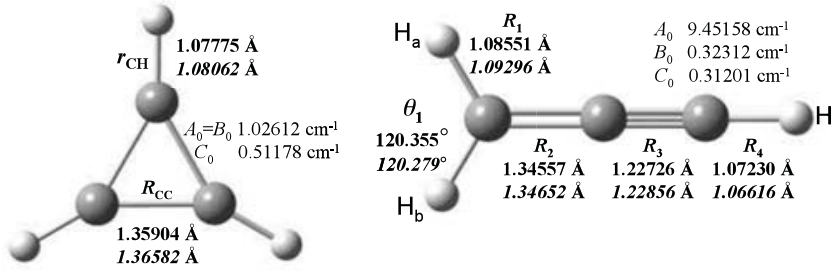

TOC Graphic 